\title{
2007 Status of Manufacturing: Polymer Electrolyte Membrane (PEM) Fuel Cells
}

D. Wheeler

DJW Technology, LLC

G. Sverdrup

National Renewable Energy Laboratory

Technical Report NREL/TP-560-41655

March 2008
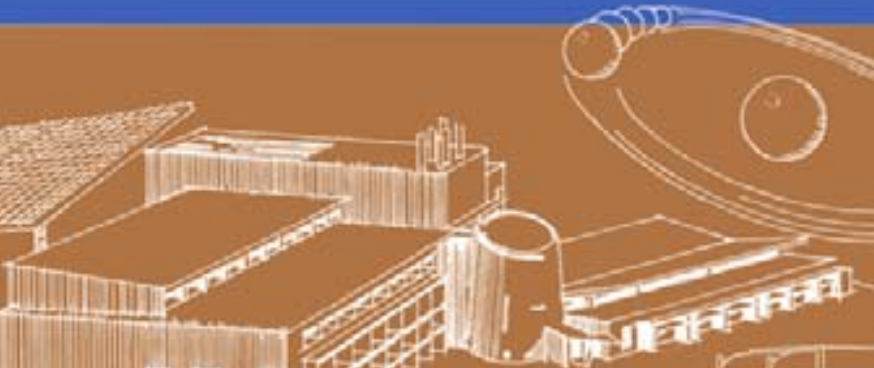


\section{Status of Manufacturing: Polymer Electrolyte Membrane (PEM) Fuel Cells}

D. Wheeler

DJW Technology, LLC

G. Sverdrup

National Renewable Energy Laboratory

Prepared under Task No. H274.1100 


\section{NOTICE}

This report was prepared as an account of work sponsored by an agency of the United States government. Neither the United States government nor any agency thereof, nor any of their employees, makes any warranty, express or implied, or assumes any legal liability or responsibility for the accuracy, completeness, or usefulness of any information, apparatus, product, or process disclosed, or represents that its use would not infringe privately owned rights. Reference herein to any specific commercial product, process, or service by trade name, trademark, manufacturer, or otherwise does not necessarily constitute or imply its endorsement, recommendation, or favoring by the United States government or any agency thereof. The views and opinions of authors expressed herein do not necessarily state or reflect those of the United States government or any agency thereof.

Available electronically at http://www.osti.gov/bridge

Available for a processing fee to U.S. Department of Energy and its contractors, in paper, from:

U.S. Department of Energy

Office of Scientific and Technical Information

P.O. Box 62

Oak Ridge, TN 37831-0062

phone: 865.576 .8401

fax: 865.576 .5728

email: mailto:reports@adonis.osti.gov

Available for sale to the public, in paper, from:

U.S. Department of Commerce

National Technical Information Service

5285 Port Royal Road

Springfield, VA 22161

phone: 800.553.6847

fax: 703.605.6900

email: orders@ntis.fedworld.gov

online ordering: http://www.ntis.gov/ordering.htm 


\section{Acknowledgments}

This work was produced for the U.S. Department of Energy's Hydrogen, Fuel Cells and Infrastructure Technologies Program. The assistance of Mr. Peter Devlin, DOE's Technology Development Manager, was instrumental in producing this report.

The authors thank Dean Armstrong for producing the fuel cell component illustrations and Julie Hasper Tuttle for her editing assistance. 


\section{Acronyms and Abbreviations}

$\begin{array}{ll}\text { BOP } & \text { balance of plant } \\ \text { CCM } & \text { catalyst-coated membrane } \\ \text { DOE } & \text { U.S. Department of Energy } \\ \text { GDE } & \text { gas diffusion electrode } \\ \text { GDL } & \text { gas diffusion layer } \\ \text { HFCIT } & \text { DOE's Hydrogen Fuel Cells and Infrastructure Technologies Program } \\ \text { kW } & \text { kilowatt } \\ \text { MEA } & \text { membrane electrode assembly } \\ \text { MRL } & \text { manufacturing readiness level } \\ \text { NREL } & \text { National Renewable Energy Laboratory } \\ \text { PEM } & \text { polymer electrolyte membrane } \\ \text { PSA } & \text { perfluorinated sulfonic acid } \\ \text { PTFE } & \text { polytetrafluoroethylene } \\ \text { PVDF } & \text { polyvinylidene fluoride } \\ \text { R\&D } & \text { research and development } \\ \text { TRL } & \text { technology readiness level }\end{array}$




\section{Contents}

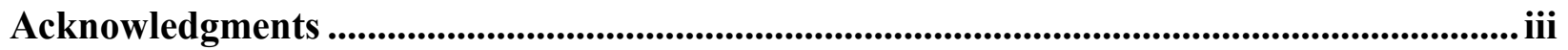

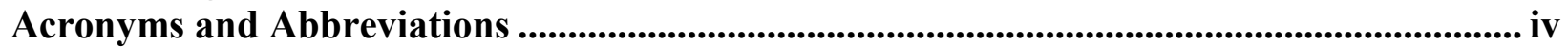

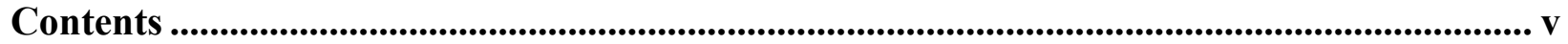

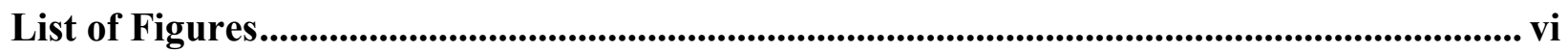

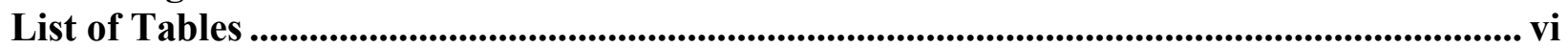

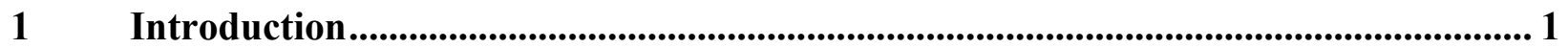

1.1 Applications for PEM Fuel Cells Included in this Assessment ................................. 1

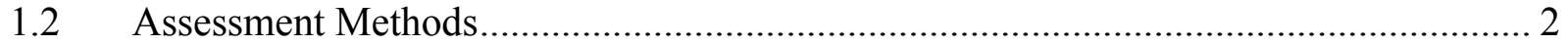

2 PEM Fuel Cell Designs and Implications for Manufacturing .................................... 3

$2.1 \quad$ Membrane Electrode Assemblies ......................................................................... 3

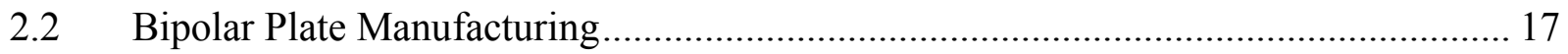

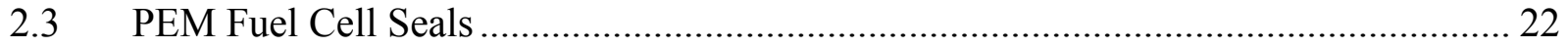

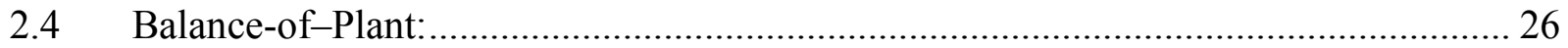

3 Status of Manufacturing and Gaps in Manufacturing Technologies for PEM Fuel

Cells ...................................................................................................................................... 34

3.1 Manufacturing Gaps for 3-Layer MEAs ................................................................. 34

3.2 Manufacturing Gaps for 5-layer MEAs ................................................................. 38

3.3 Manufactuirng Gaps for Bipolar Plates .................................................................... 39

3.4 Manufacturing Gaps in Seal Application for MEAs, Cells, and Cell Stacks .............. 40

3.5 Manufacturing Gaps in Cell Stack Assembly ........................................................ 40

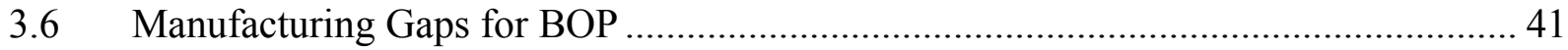

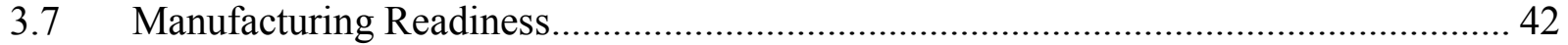

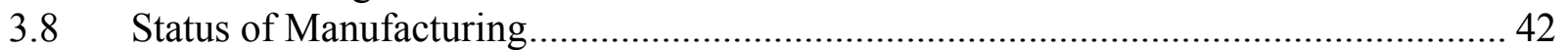

$4 \quad$ Recommendations ................................................................................................. 45

4.1 Manufacturing R\&D Gaps .................................................................................. 45

4.2 Concurrent Technology Development \& Manufacturing R\&D ............................... 48

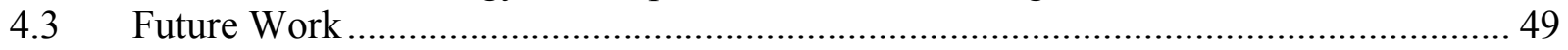

Appendix A. Manufacturing Tools................................................................................... 51 


\section{List of Figures}

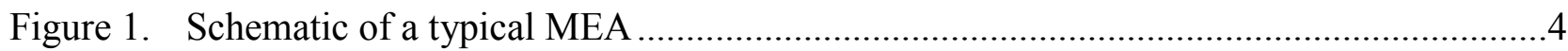

Figure 2. The carbon felt, carbon paper, or graphite cloth are bonded to the CCM using a seal around the edges of the gas diffusion layer.

Figure 3. Decal transfer of the catalyst layer by hot pressing or hot roll pressing is used to transfer the preformed catalyst layer onto the PSA membrane.

Figure 4. A GDE is comprised of a GDL (anode GDL shown), microlayer, and catalyst layer......9

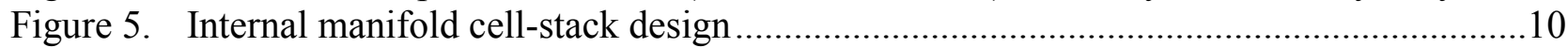

Figure 6. Cell stack with a combination internal-external manifold .................................................10

Figure 7. Material loss in membrane manufacturing approach...................................................11

Figure 8. Stresses within the MEA at the catalyst-edge seal interface.........................................13

Figure 9. Cell with catalyst-coated membrane for an external manifold design with the corners removed to allow the coolant to enter and exit the bipolar plate.

Figure 10. Alternative external-manifold planform with the coolant entering along one side. In this design the catalyst-coated membrane could have an edge-to-edge configuration...........15

Figure 11. Thin-strip sealing zone of the CCM...........................................................................

Figure 12. The complete bipolar plate is assembled by bonding the flat side of the anode bipolar plate to the coolant flow side of the cathode bipolar plate. ............................................19

Figure 13. Cross section of metallic bipolar plate showing contacts to adjacent cells. ...................20

Figure 14. Schematic of cell misalignment in cell stack .................................................................21

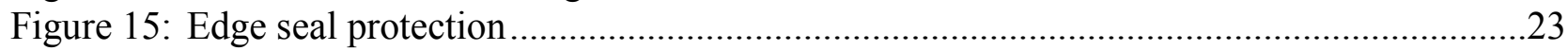

Figure 16. Design of the flow field in an internal manifold showing extrusion of seal...................24

Figure 17. Seals are designed to have height and compressive properties that assure the GDLs, the catalyst layers, and the membranes remain in contact for water/proton transport...........25

Figure 18: Schematic diagram of pressurized PEM fuel cell system...............................................28

Figure 19. Alternative diagram of atmospheric PEM fuel cell system ............................................29

Figure 20: Roll processing process for depositing catalyst layers formed with edge seals using the decal transfer method; from 3M patent U.S. 7,195,690..............................................37

\section{List of Tables}

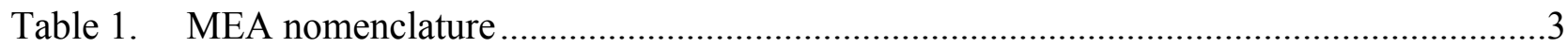

Table 2. Bipolar plate manufacture concepts .......................................................................18

Table 3. Comparison of BOP for pressurized design and atmospheric design PEM fuel cells ....30

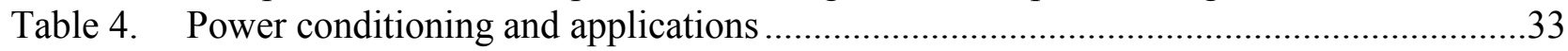

Table 5. The balance of plant components and manufacturers ......................................................42

Table 6. Manufacturing readiness levels...................................................................................49 


\section{Introduction}

In this document we assess the North American industry's current ability to manufacture polymer electrolyte membrane (PEM) fuel cells. The U.S. Department of Energy (DOE) commissioned this assessment as part of the manufacturing research and development (R\&D) activity within its Hydrogen, Fuel Cells and Infrastructure Technologies Program. The results will be used by DOE to prioritize and guide its manufacturing R\&D projects.

The manufacturing R\&D activity, which began in fiscal year 2007, uses the results from DOE's 2005 workshop on Manufacturing R\&D for the Hydrogen Economy. ${ }^{1}$ Recommendations from the workshop and other input from North American manufacturers are guiding DOE's goals, objectives, and research tasks. ${ }^{2}$

This assessment explores the following topics:

- The readiness of PEM fuel cell stack components for manufacturing at several levels for different applications, e.g., portable PEM or backup power

- The readiness of PEM fuel cell systems for manufacturing and assembly.

\subsection{Applications for PEM Fuel Cells Included in this Assessment}

This assessment considers the following applications for PEM fuel cells:

- Portable PEM-based fuel cell systems with power ratings of less than 1 kilowatt $(\mathrm{kW})$; typically used in applications where 1 to 100 watts are required. Portable PEM fuel cells include hydrogen-fueled, direct-methanol-fueled, and reformed-methanol-fueled PEM fuel cells.

- Backup power and remote power PEM fuel-cell systems with power ratings of $1 \mathrm{~kW}$ to 5 $\mathrm{kW}$. Hydrogen is the fuel for these applications.

- Residential power PEM fuel-cell systems with power ratings of $1 \mathrm{~kW}$ to $10 \mathrm{~kW}$. These systems typically operate with an on-site reformer. The choice of fuels includes methanol, methane (natural gas), and propane.

- Stationary power PEM fuel-cell systems operating at power ranges from $50 \mathrm{~kW}$ to 250 $\mathrm{kW}$. These systems operate with an on-site reformer. Methane is the typical fuel for these systems.

- Industrial vehicles powered by $10 \mathrm{~kW}$ to $50 \mathrm{~kW}$ PEM fuel cells. These vehicles include forklifts and people movers. Hydrogen is the fuel of choice for these applications.

- Automotive PEM fuel cells with PEM systems power ratings from $50 \mathrm{~kW}$ to $100 \mathrm{~kW}$. Hydrogen is the fuel of choice for the light-vehicle applications.

- PEM systems with power ratings from $100 \mathrm{~kW}$ to $300 \mathrm{~kW}$ for heavy-duty vehicles such as buses. Hydrogen is the fuel of choice for these applications.

\footnotetext{
${ }^{1}$ DOE Manufacturing Workshop Web site: www.eere.energy.gov/hydrogenandfuelcells/wkshp_h2_manufacturing.html

2 Hydrogen, Fuel Cells \& Infrastructure Technologies Program: Multi-Year Research, Development and Demonstration Plan -

Planned program activities for 2003-2010, DOE Office of Energy Efficiency and Renewable Energy, Section 6.0, April 27, 2007.
} 
Some manufacturing requirements are common to all the applications listed above and these will be discussed in the following sections without mentioning specific applications. Unique manufacturing requirements are associated with the size of the cell stack and the type of fuel required for each application.

\subsection{Assessment Methods}

For this report we interviewed several companies in the fuel cell industry and complemented the interviews with a review of published technical papers and trade journals. Industry leaders were asked to identify current manufacturing methods as well as barriers to high-volume, low-cost PEM fuel cell manufacturing. We examined the literature to identify PEM fuel cell trends, developments, and manufacturing constraints.

We interviewed the following organizations.

3M, Inc.

Arkema Group

Ballard

Cabot Superior Micropowders

Dana Corporation

DuPont Fuel Cells

Edison Materials Technology Center

Entegris, Inc.

E-TEK Division of PEMEAS (now BASF)

GE Global Research

GrafTech Advanced Energy Technology, Inc.

Honeywell

Hydrogenics

Parker Hannifin

Plug Power Inc.

Rensselaer Polytechnic Institute

SGL

Stratum Technologies, Inc.

UTC Power

W.L. Gore \& Associates 


\section{PEM Fuel Cell Designs and Implications for Manufacturing}

\subsection{Membrane Electrode Assemblies}

The membrane electrode assembly (MEA) is a basic building block of fuel cells. The MEA has five basic components:

Membrane

Anode catalyst layer

Cathode catalyst layer

Anode gas diffusion layer (GDL)

Cathode GDL.

Figure 1 is a schematic of a typical MEA and each of these five components. The terms used to identify MEA components vary between companies because of the independent development of PEM fuel cells. The different terms are listed in Table 1.

Table 1. MEA nomenclature

\begin{tabular}{l|l}
\hline \multicolumn{1}{c|}{ Term } & \multicolumn{1}{c}{ Definition } \\
\hline 3-layer structure & $\begin{array}{l}\text { Anode and cathode catalyst layers with a membrane inserted } \\
\text { between the catalyst layers forms a catalyst coated membrane } \\
\text { (CCM) } \\
\text { CCM with the addition of the anode and cathode GDLs (includes } \\
\text { a micro-layer on the GDLs) }\end{array}$ \\
7-layer structure & $\begin{array}{l}\text { Membrane with the addition of anode and cathode gas diffusion } \\
\text { electrodes (GDE). GDEs have the microlayer and catalyst layer } \\
\text { bonded to the GDL. } \\
\text { Evolved from the development of the micro-layer on the GDL; } \\
\text { however, this term is not in common usage. }\end{array}$ \\
\hline
\end{tabular}

In this analysis, the term "MEA" means a 5-layer structure that includes the micro-layers. We will also use the term "CCM," which is synonymous with a 3-layer structure. 


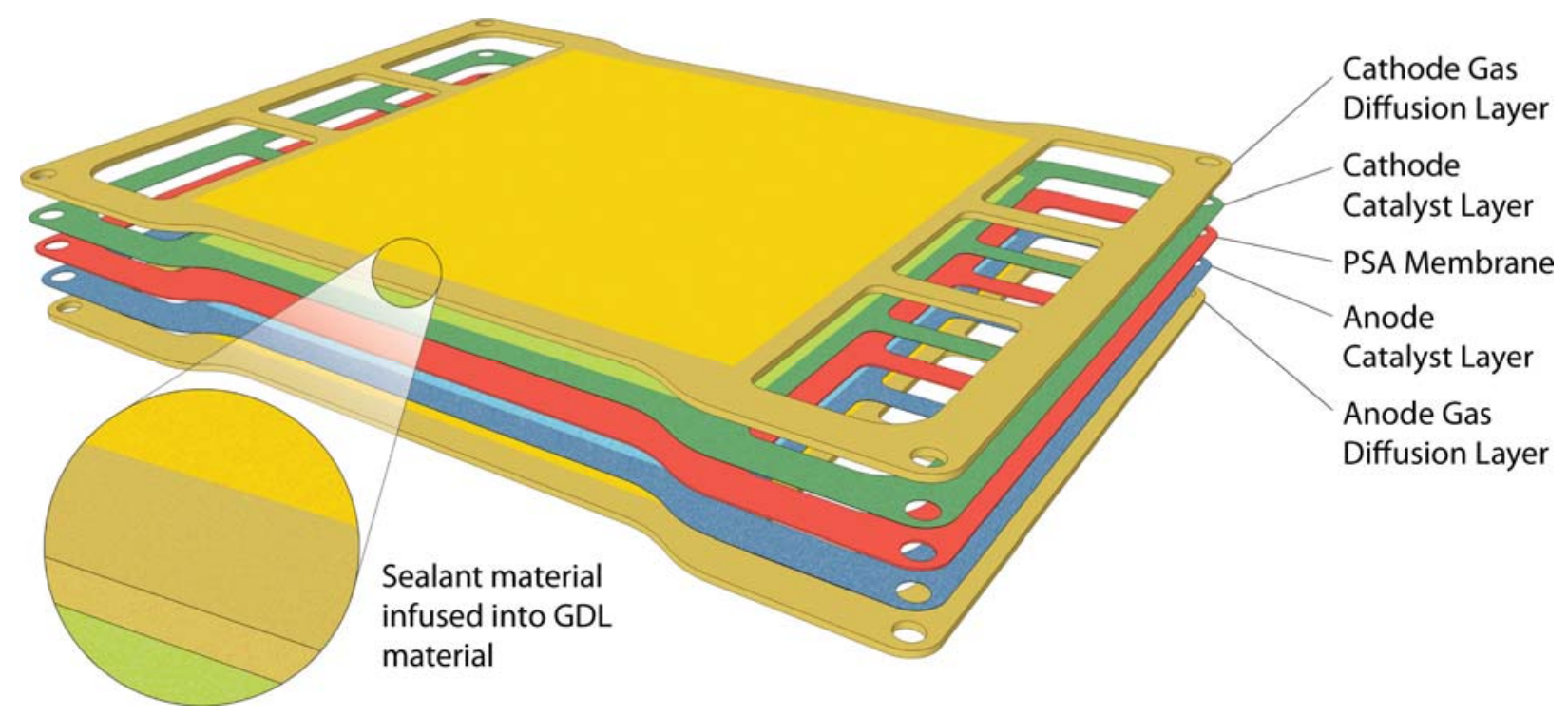

Figure 1. Schematic of a typical MEA

\subsubsection{Composition of MEA}

An MEA includes membrane, anode and cathode catalyst layers, and gas diffusion layers.

\subsubsection{Membrane Layer}

For this analysis, the membrane material is perfluorinated sulfonic acid (PSA) unless otherwise noted. In some cases, the membrane is reinforced with polytetrafluoroethylene (PTFE) for added mechanical strength as in the membranes made by W.L. Gore \& Associates.

\subsubsection{Catalyst Layers}

The catalyst layers are created by depositing precious metals on a carbon-particle support. For the anode, the precious metal can be either platinum or platinum-ruthenium alloy. For the cathode, the precious metal can be platinum or platinum-cobalt alloy.

The carbon-particle support used by many manufacturers is the Ketjenblack EC300. The Vulcan XC-72 manufactured by Cabot Corporation is another commonly used support for the precious metal catalyst. In addition, Cabot Superior Micropowders has developed alternative carbon supports that are concurrently formed with the catalyst. Some manufacturers are using these catalysts in direct methanol fuel cells. The carbon supports are limited by carbon corrosion at high potentials. Researchers at $3 \mathrm{M}$ report that they are developing a process to deposit platinum on organic-pigment crystalline-whisker supports. The pigment particles replace the catalyzed carbon supports.

The catalyzed carbon is either deposited on the membrane (the CCM manufacturing approach) or deposited onto the GDL (the GDE manufacturing approach). PSA ionomer is infused into the catalyst layers; often from an alcohol solution. The PSA ionomer must be thermally treated to cure the ionomer and assure its stability in PEM fuel cell operation. Hot pressing cures the ionomer. The ionomer promotes the transport of protons through the catalyst layer since proton transport across the carbon particles is hindered. A catalyst layer that will have precious metal nano-particles deposited on carbon will include a PSA ionomer. 
Catalyst layers containing unsupported platinum blacks (fine particles of platinum) do not need the ionomer addition. Protons move rapidly over platinum black surfaces.

\subsubsection{Gas Diffusion Layers}

A GDL is constructed from carbon cloth, carbon paper, or carbon felts. Carbon cloths are typically prepared by weaving carbon or graphite fibers. Carbon papers are prepared from a slurry of carbon particles and fibers that form a pulp that is cast and dried. Carbon felts contain a high carbon fiber content that are processed with felting machines that use needles to disperse the carbon fibers in three dimensions. The felting process increases the strength of the carbon paper.

The thickness, porosity, air permeability, and electrical resistance are important properties that can be modified to provide the specific property requirements. The micro-layer on the GDL is made up of carbon particles and PTFE. The GDLs are bonded to the catalyst layers in the CCM manufacturing approach or have the catalyst layer deposited on GDL in the GDE manufacturing approach.

The micro-layer on the carbon paper, carbon cloth, or carbon felt used for the GDL assists in transporting and distributing liquid water to and from the catalyst layer. The micro-layer is instrumental in transporting the reactant gases. Some, but not all, carbon micro-layers are fabricated from the same materials as the Ketjenblack or XC-72 carbon supports. Additives such as Teflon provide a way to control the hydrophobic properties of the micro-layer.

\subsubsection{Baseline Methods for Manufacturing MEAs}

In this analysis, the predominant two methods for manufacturing MEAs are considered.

Catalyst coated membrane (CCM) manufacturing

Gas diffusion electrode (GDE) manufacturing.

\subsubsection{CCM Manufacturing}

CCM manufacturing deposits the catalyst onto each side of the membrane. We examine two methods for depositing the catalyst.

Direct deposition: screen printing, ink jet printing, doctor blade coating, or slot die deposition of the catalyst layer directly onto the membrane.

Decal transfer: screen printing, ink jet printing, doctor blade coating, or slot die deposition of the catalyst layer on an alternative support and then transferring the catalyst layer to the membrane by hot pressing.

GDLs are applied at the end of the CCM manufacturing process. As previously mentioned, the GDL has a micro-layer of carbon deposited on the surface that interfaces with the catalyst layer attached to the membrane. The carbon felt, carbon paper, or graphite cloth are bonded to the CCM using a seal around the edges of the gas diffusion layer as shown in Figure 2. The bonding can be achieved through hot pressing or hot roll pressing to cure the sealant.

Direct deposition of the catalyst onto the membrane is difficult, especially for the water-saturated PSA membrane. This is because PSA membranes have a very low tear resistance $(1100 \mathrm{gf} / \mathrm{mm})$. 
It is possible to deposit a dry-film catalyst, but the process is complicated by the swelling of the membrane when the membrane is hydrated. The hydration process induces in-plane compression in the friable membrane, and the membrane creeps to relieve these stresses. ${ }^{3}$ The swelling can cause the membrane to fail. Industry response to our questions suggests some companies have developed the ability to coat catalyst onto a fully hydrated PSA membrane. Direct coating onto the hydrated reinforced membrane appears to be a successful technique for manufacturing the catalyst-coated membrane. The reinforcement provides additional strength to the hydrated membrane.

Screen printing, ink jet printing, and doctor blade coating the catalysts onto the membranes can be detrimental because the solvents and suspension agents used in the inks and slurries may be absorbed into the membrane. These processing agents may impede proton transport in the membrane or cause poor transport of water through the membrane.

PSA ionomer is added to the catalyst layer to promote the transport of protons and water in the catalyst layers. The PSA ionomer is added as a solution in concentrations ranging from $10 \%$ to $50 \%$ with ethanol or some other alcohol as the solvent. The solvent is evaporated, leaving a film of PSA on the carbon-supported catalyst. The PSA ionomer must be further heat treated for stability. Two approaches for curing the ionomer are hot pressing and hot roll pressing.

The heat-treatment of the ionomer was identified by some, but not all, manufacturers as a barrier to high-rate CCM manufacturing. Hot pressing requires a discrete processing step that interrupts continuous fabrication. The hot pressing process typically requires 90 seconds; this would limit production to $40 \mathrm{MEAs}$ per hour on a single line. Membrane dehydration during the heat treatment process is also a manufacturing concern and could be a manufacturing barrier.

Decal transfer resolves the problems of printing or doctor-blade coating the catalyst onto the fragile membrane. The catalyst layers, including the ionomer content, are deposited on an alternative substrate and heat treated to remove the solvents and to bond the catalyst layers. The alternative support is a thick, more resilient polymer film with an inert composition such as polyvinylidene difluoride (PVDF) or polyester. Decal transfer of the catalyst layer by hot pressing or hot roll pressing is used to transfer the preformed catalyst layer onto the PSA membrane (see Figure 3). This process uses a fully hydrated PSA membrane. Additional dissolved ionomer can be added to assure a tight bond between the catalyst layer and the membrane; however this approach requires an additional curing step.

\footnotetext{
${ }^{3}$ Rohit Makharia, Shyam S. Kocha, Paul T. Yu, Craig Gittleman, Daniel Miller, Chris Lewis, Frederick T. Wagner, Hubert A. Gasteiger, $208^{\text {th }}$ Meeting of The Electrochemical Society, Abstract\# 1165, Los Angeles , CA, October 1621,2005
} 


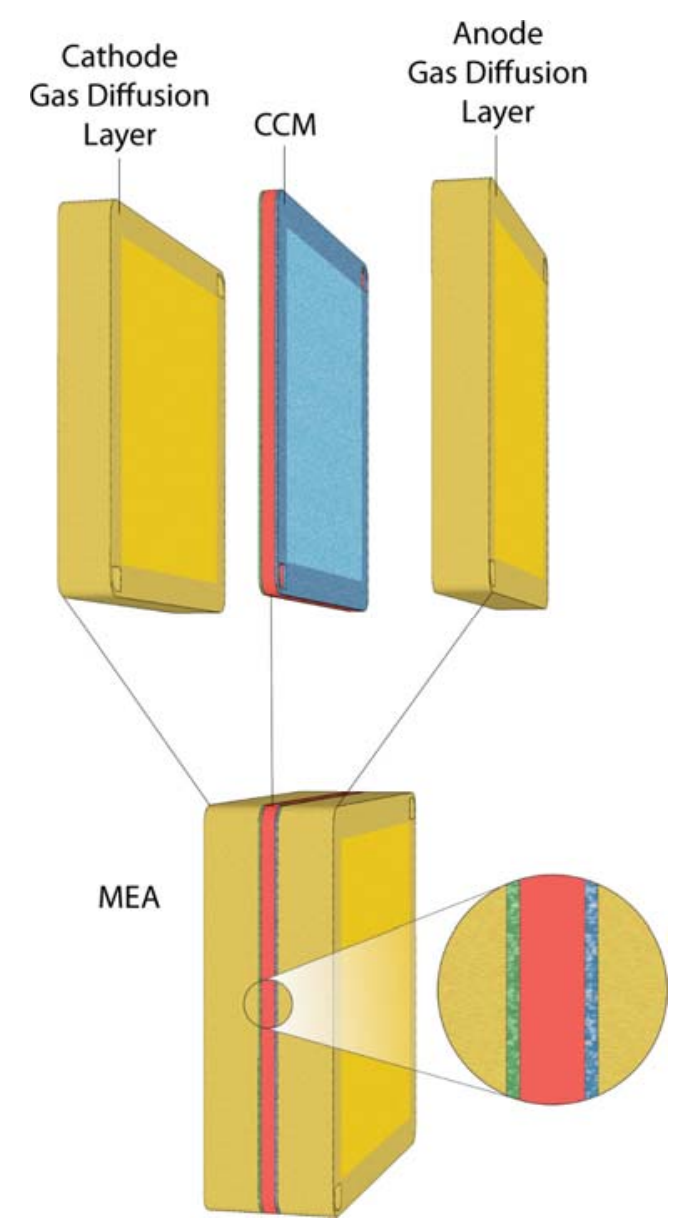

Figure 2. The carbon felt, carbon paper, or graphite cloth are bonded to the CCM using a seal around the edges of the gas diffusion layer. 


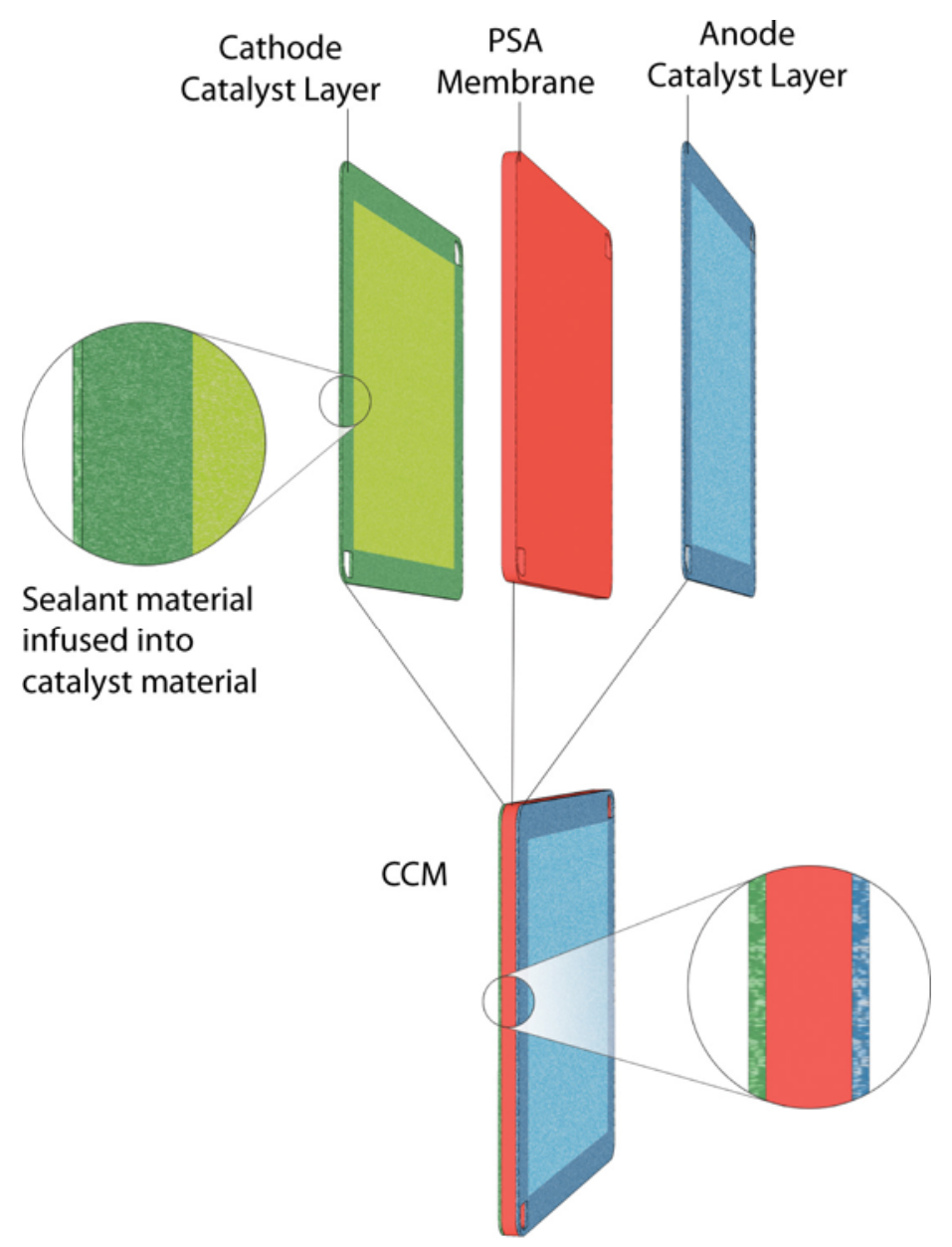

Figure 3. Decal transfer of the catalyst layer by hot pressing or hot roll pressing is used to transfer the preformed catalyst layer onto the PSA membrane.

Evolution of the design of PEM fuel cell to low catalyst loadings could provide the opportunity to deposit catalyst onto the membrane or GDL by means of vacuum deposition. Manufacturing methods consistent with thin film production for photovoltaic devices would provide new avenues for manufacturing CCMs.

\subsubsection{GDE Manufacturing}

The GDE process for manufacturing MEAs eliminates the difficulties associated with directly depositing the catalyst onto the membrane. In the GDE process, the catalyst layer is directly coated on top of the GDL as shown in Figure 4. Screen printing, ink jet printing, and doctor blade coating are methods that have been successfully used for GDE manufacturing. The screen printing, ink-jet printing, and doctor blade processes are greatly simplified because processing agents can be leached or evaporated out of the catalyst layer during the formation of the GDE and prior to bonding the GDE to the PSA membrane.

The GDE process uses a PSA ionomer to assist in proton and water transport between the catalyst layer and the membrane. Heat treatment curing of the ionomer to remove the solvent and to cure the PSA is required. 
In the MEA manufacturing process the anode GDE and the cathode GDE are bonded to the membrane as shown in Figure 4. In some cases manufacturers use a hot-pressing process or a hot-roll-pressing process. In this process there are two main issues:

Hot pressing the GDEs into the fragile PSA membrane

Water loss from the membrane during the hot pressing process.

Both issues are potential barriers to manufacturing MEAs using the GDE process.

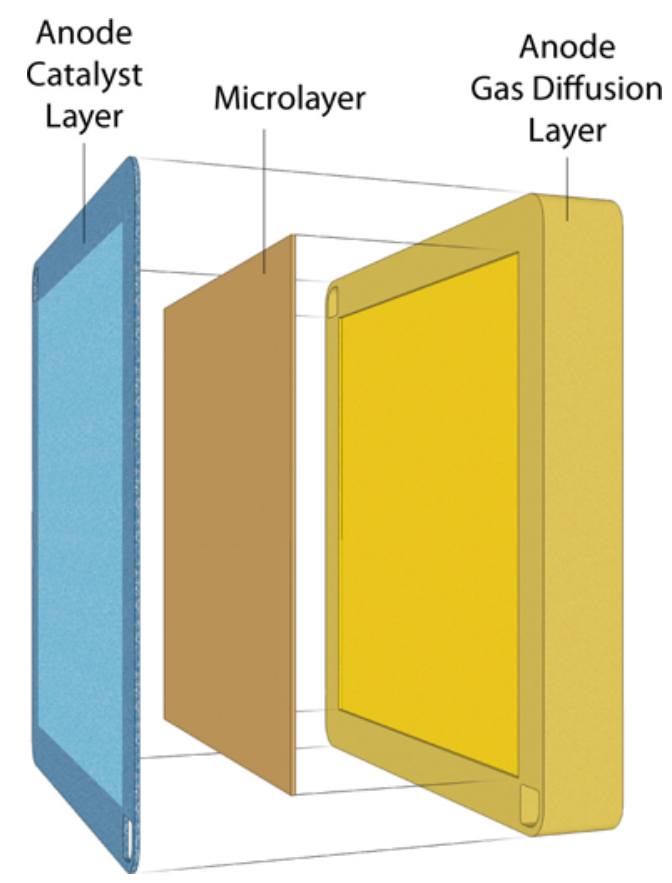

Figure 4. A GDE is comprised of a GDL (anode GDL shown), a microlayer, and a catalyst layer.

\subsubsection{Manufacturing the MEA with Various Manifold Configurations}

The manufacture and design of the MEA is strongly influenced by the manifold design. The manifolds provide the pathways for the reactants and coolant to enter and exit the cell and cell stack. The planform of a cell is the design of the cell including the active area of the cell and the manifolds.

The three approaches to fuel-cell stack design used in PEM technology are:

Cell stacks with internal manifolds

Cell stacks with external manifolds

Cell stacks with a combination of internal and external manifolds. 
The planform for an internal manifold cell-stack design is represented in Figure 5 and the planform for a cell stack with a combination internal-external manifold is shown in Figure 6. (Cells with all external manifolds are shown in Figure 9 and Figure 10.)

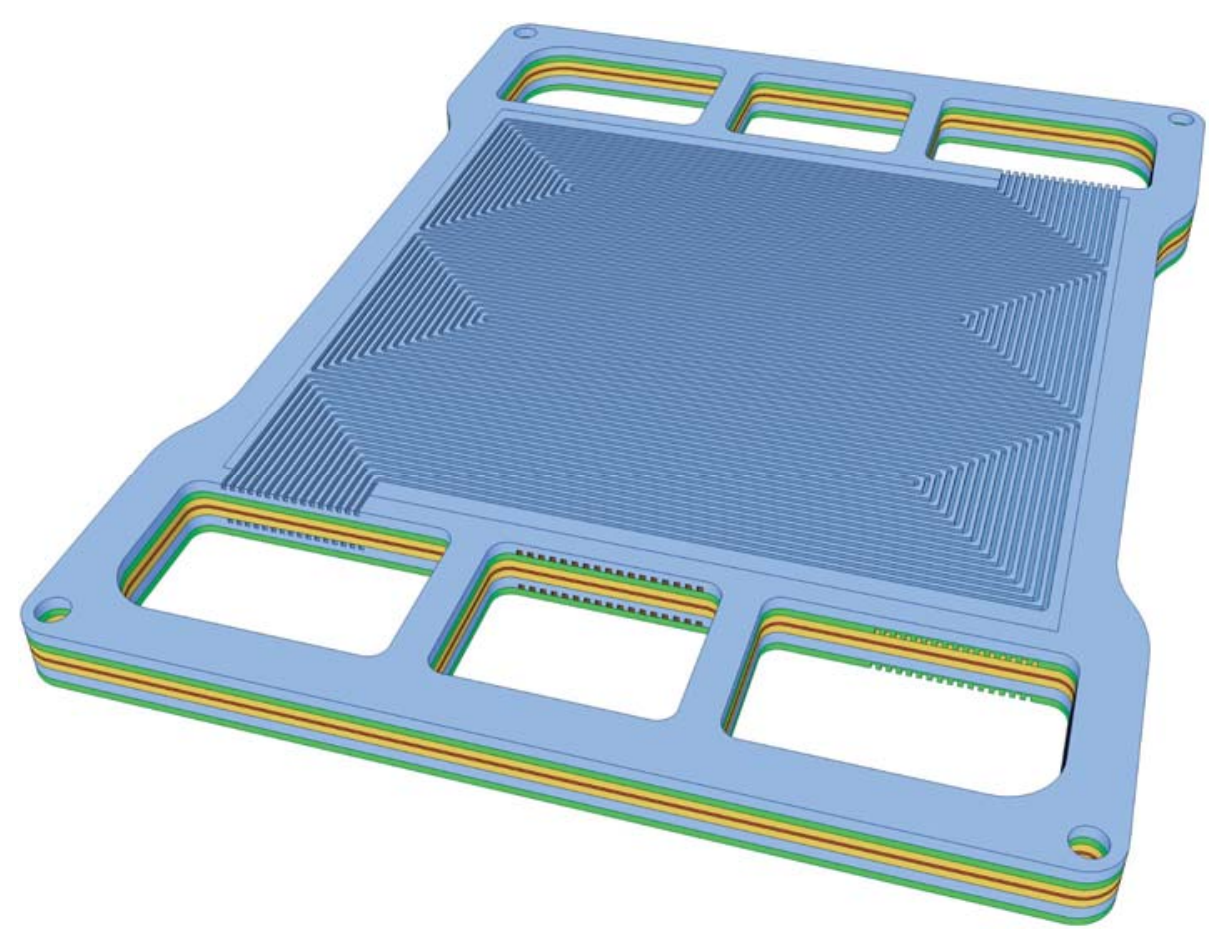

Figure 5. Internal manifold cell-stack design

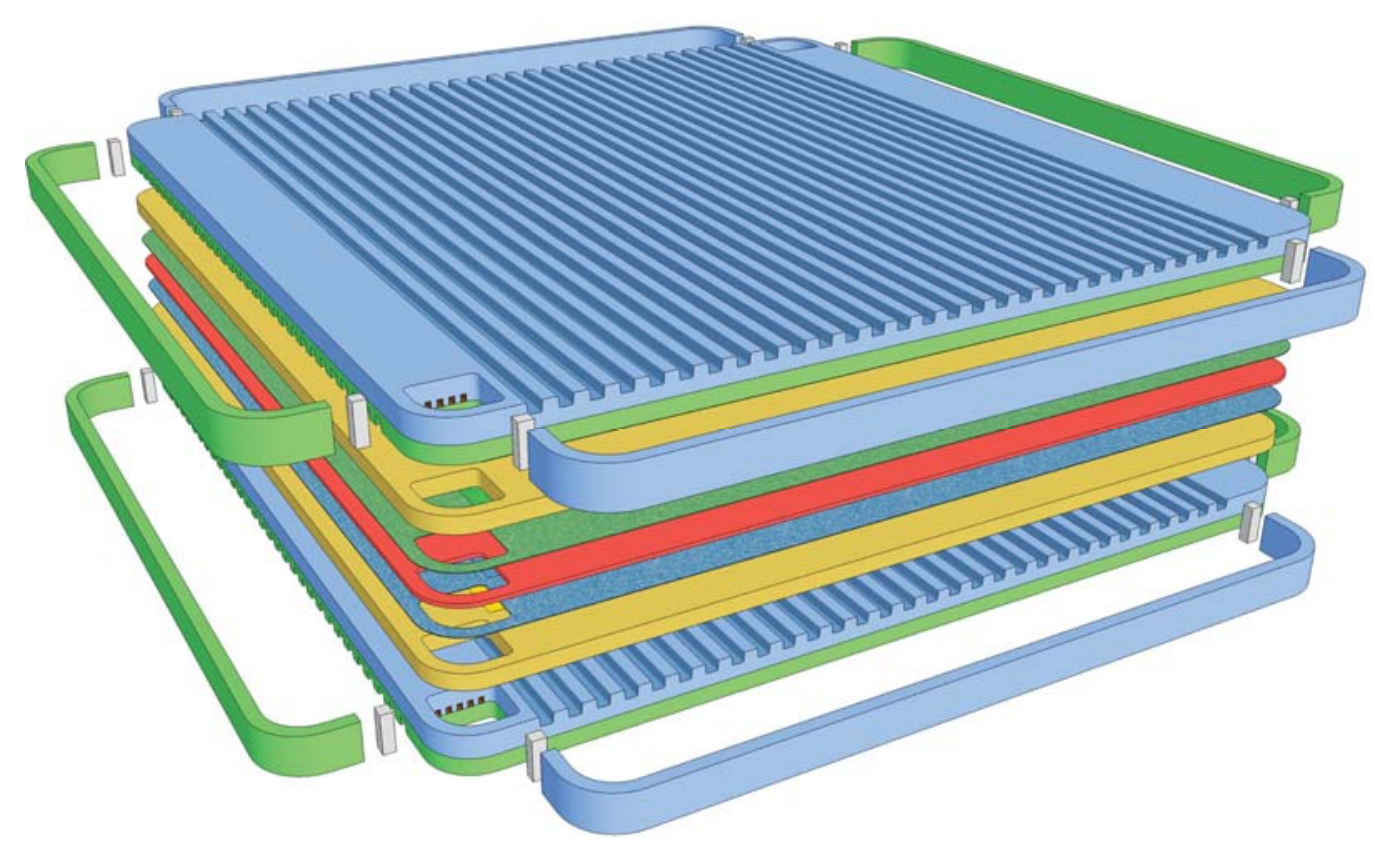

Figure 6. Cell stack with a combination internal-external manifold 


\subsubsection{Cell Stacks with Internal Manifolds}

Figure 5 shows the planform of a bipolar plate with the reactants and coolant delivered and removed using internal manifolds.

There are three manufacturing approaches for the MEA used in a cell stack with internal manifolds:

1. Fabricate continuous sheets of catalyst-coated membrane with dimensions equal to the planform outer dimensions

2. Selectively deposit the catalyst on a continuous sheet of membrane with the catalyst layer only covering the active region of the cell

3. Bond the catalyst-coated membrane to a prefabricated manifold.

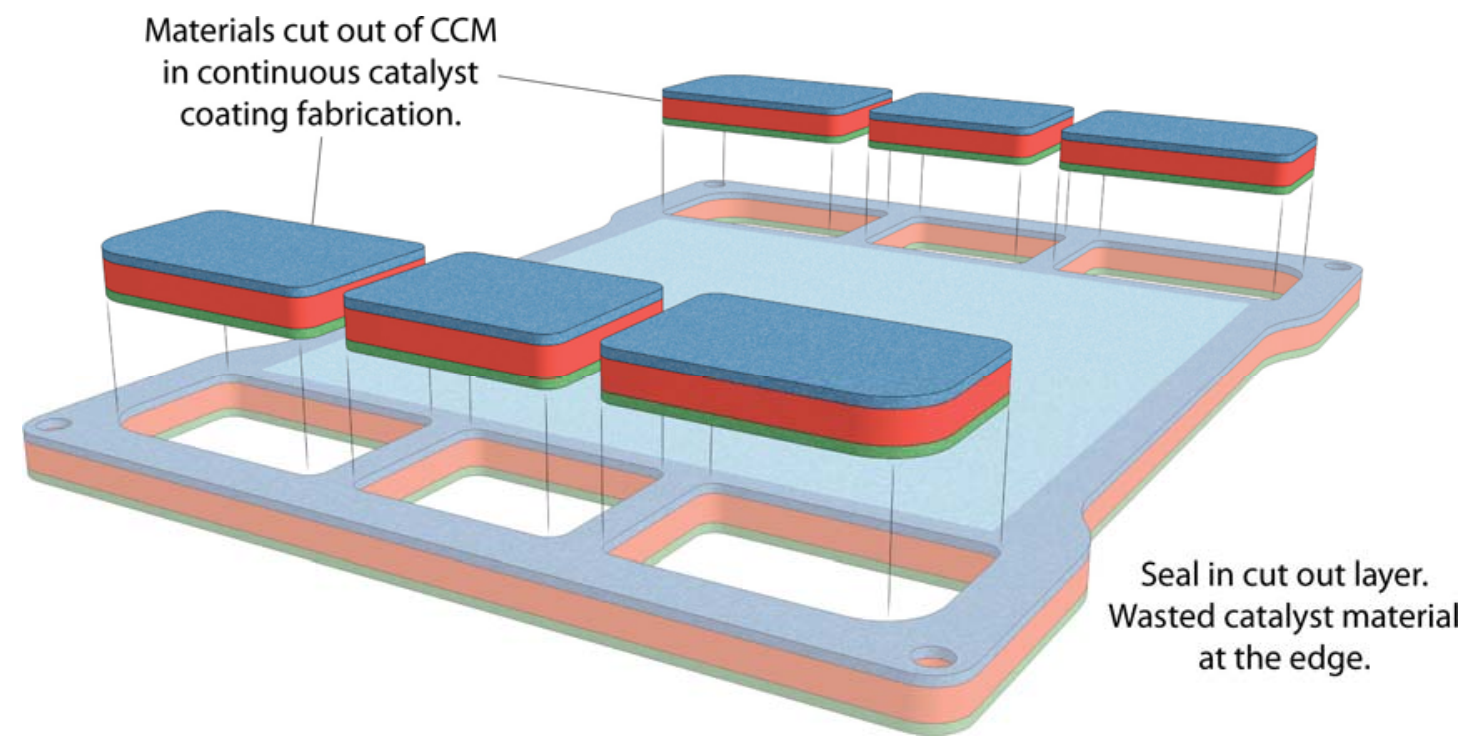

Figure 7. Material loss in membrane manufacturing approach

\section{Internal Manifold Manufacturing Approach 1: Continuous Catalyst Coating of the Membrane}

Fabricating a continuous catalyst coating over the membrane is consistent with high volume production using roll-to-roll processing. The catalyst coats the entire membrane from edge to edge and the full length of the membrane roll. This type of processing is well established and processing costs are low. This is a primary advantage of this processing method.

However, this approach wastes catalyst. The catalyst-coated membrane will have excess catalyst that will be lost when the manifold openings are cut. This is a loss of a high-cost precious metal that has value-added processing; the material lost is schematically shown in Figure 7. Because the precious metal can represent $70 \%$ of the MEA cost, this approach is not viable.

Additionally, seals need to be attached at the manifold inlets and exits to prevent the coolant from mixing with either catalyst layer. The seals will block a portion of the catalyst at the 
internal manifold-catalyst interfaces. The catalyst loss for a $25 \mathrm{~cm} \mathrm{x} 18 \mathrm{~cm}$ planform with internal manifolds and continuous catalyst coating can be as high as $40 \%$ or $50 \%$ of the catalyst. With this manufacturing approach, a nominal $0.25 \mathrm{mg} \mathrm{Pt} / \mathrm{cm}^{2}$ loading for a MEA would have a usage factor of $50 \%$ to $60 \%$; i.e., $40 \%$ to $50 \%$ of the catalyst is lost in manufacturing. The loading cost would be equivalent to a $0.5 \mathrm{mg} \mathrm{Pt} / \mathrm{cm}^{2}$ loading; or twice the catalyst cost.

As shown in Figure 5, the seals have a complex shape. Matching the height and compressive properties of the seal to the catalyst layer is necessary to avoid stress when the cell stack is under compressive load. Applying a liquid seal that penetrates the catalyst layer in the sealing areas but does not contaminate the active areas of the catalyst layer is a difficult manufacturing problem.

\section{Internal Manifold Manufacturing Approach 2: Selective Catalyst Deposition on the Membrane}

In this manufacturing approach, the membrane covers the full planform of the cell. Catalyst is selectively deposited onto the membrane only in the electroactive region of the cell. An edge seal is applied to the rest of the membrane. The membrane and edge seal will need to be cut out to accommodate the manifolds. This approach reduces the catalyst loss during manufacturing.

Selectively depositing the catalyst over the active area of the membrane requires a high resolution deposition process. Screen printing and ink-jet printing are two manufacturing methods for depositing catalyst layers with the necessary control.

The production rates for selective deposition of the catalyst layer on the membrane will be slower than the edge-to-edge roll processing discussed previously. The regions of the membrane not covered by the catalyst will require an edge seal material that has a height and durometer (measure of hardness) equal to that of the catalyst layer. This is necessary to minimize stresses within the MEA at the catalyst-edge seal interface; the point of stress is schematically shown in Figure 8. Applying the edge seal will require the same precision as applying the catalyst layer.

\section{Internal Manifold Manufacturing Approach 3: Bonding the Catalyst-Coated Membrane to the Manifold}

Bonding the catalyst-coated membrane to a prefabricated manifold permits the use of continuous catalyst-coated membrane. This approach would involve roll-to-roll processing to deposit the catalyst layer, and manufacturing a separate manifold with cut-outs for the catalyst-coated membrane and the internal manifold connections. Manufacturers would need to establish a seal to bond the separate manifold and the CCM. The height and durometer of the separate manifolds would have to match that of the catalyst layer to avoid stress on the MEA when under compressive load in the cell stack. The stress points are identified in Figure 8.

Aligning and sealing the separate manifold with the catalyst-coated membrane presents a manufacturing problem. The two components need to overlap in order to bond properly. Tapering the edges of the manifold and CCM to form an overlap region for bonding is one approach. Butt welding the very thin layers may be very difficult and may increase the thickness at the bond, which would create a stress point when the cell stack is under compressive load. Controlling the registration, alignment, and bond thickness can slow down the manufacturing process. 


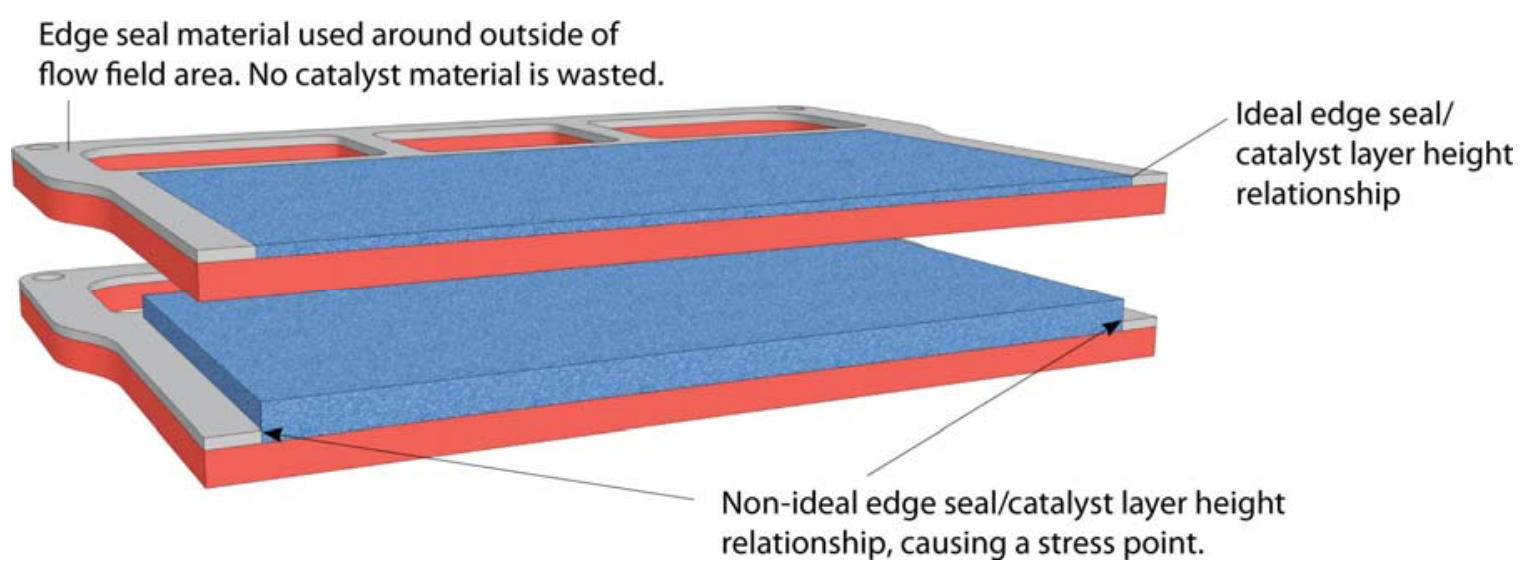

Figure 8. Stresses within the MEA at the catalyst-edge seal interface

\subsubsection{Cell Stacks with External Manifolds}

The external manifold approach eliminates the need to have cut-outs in the MEA for the reactant and coolant inlets and exits. The external manifold process complicates the design of the planform and the bipolar plates because it requires six ports; three inlet ports and three outlet ports. The six-port configuration does not use rectangular MEAs, and continuous roll coating of an irregular MEA configuration would complicate fabrication. One design approach is to make the coolant ports much smaller than the reactant inlet and outlet ports. The coolant ports would be cut from a rectangular MEA after catalyst coating; the sections cut from the MEA would contribute to the precious metal scrap. The use of external manifolds assists in the cell stack assembly.

An advantage of the external manifold system is the ability to simplify bipolar plate flow field fabrication. This will be discussed in the Bipolar Plate Manufacturing section.

There are three approaches to manufacturing the MEA used in a cell stack with external manifolds:

Fabricate continuous sheets of catalyst-coated membrane with dimensions equal to the planform outer dimensions

Selectively deposit the catalyst on a continuous sheet of membrane with the catalyst layer only covering the active region of the cell

Bond the catalyst-coated membrane to a prefabricated manifold. 


\section{External Manifold Manufacturing Approach 1: Continuous Catalyst Coating of the Membrane}

External manifold designs facilitate continuous-catalyst coating over the membrane, which is consistent with high volume roll-to-roll processing. As stated previously, this type of processing is well established and processing costs are considered to be low. Catalyst use can be optimized with this approach since the active area extends to a narrow seal at the edges of the planform. A $15 \mathrm{~cm} \times 15 \mathrm{~cm}$ area with a $1.3 \mathrm{~cm}$ edge seal around the active area, i.e., $15 \%$ of the catalyst area is covered by seal and unavailable to the fuel cell reactants. A nominal $0.25 \mathrm{mg} \mathrm{Pt} / \mathrm{cm}^{2}$ loading for an MEA would have a usage factor of $85 \%$ and the actual platinum loading used would be equivalent to a $0.285 \mathrm{mg} \mathrm{Pt} / \mathrm{cm}^{2}$ loading.

There would be no losses associated with the reactant inlets and outlets as shown in Figure 9 and Figure 10.

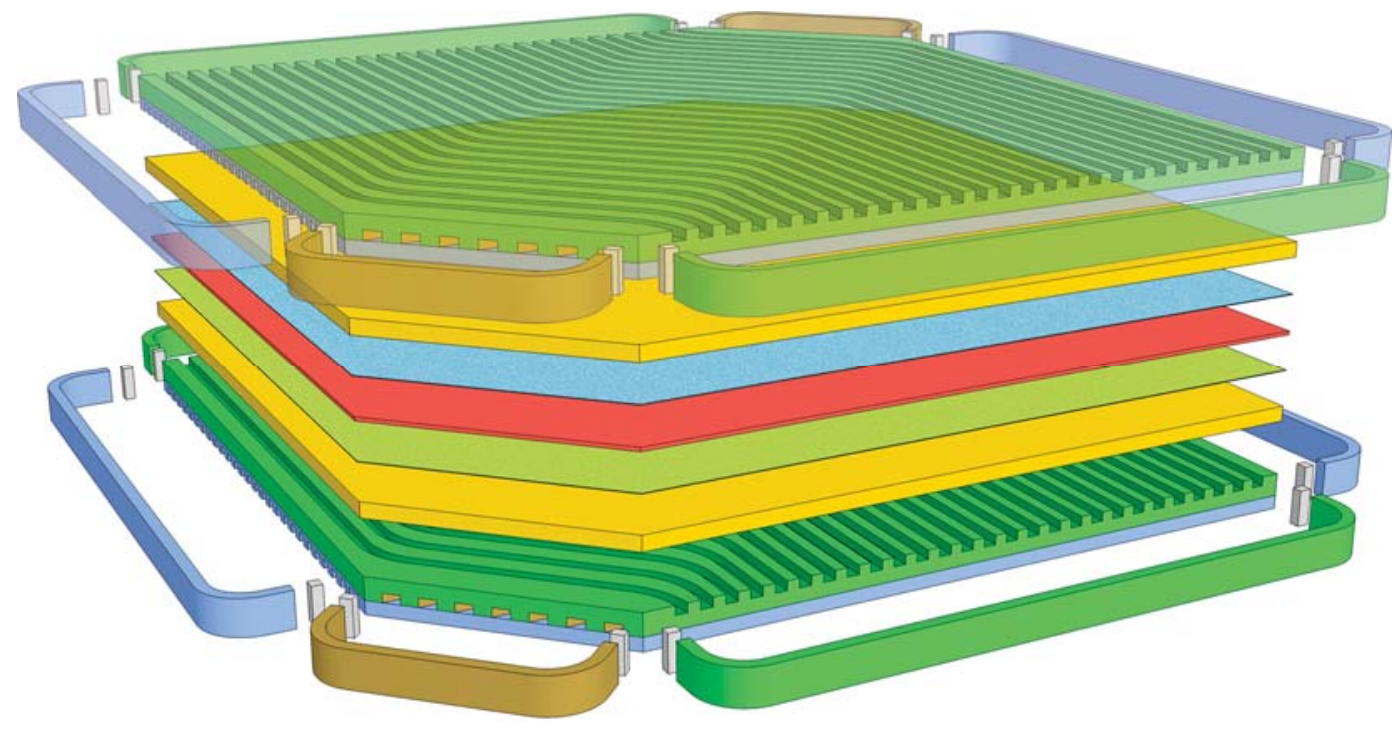

Figure 9. Cell with catalyst-coated membrane for an external manifold design with the corners removed to allow the coolant to enter and exit the bipolar plate 


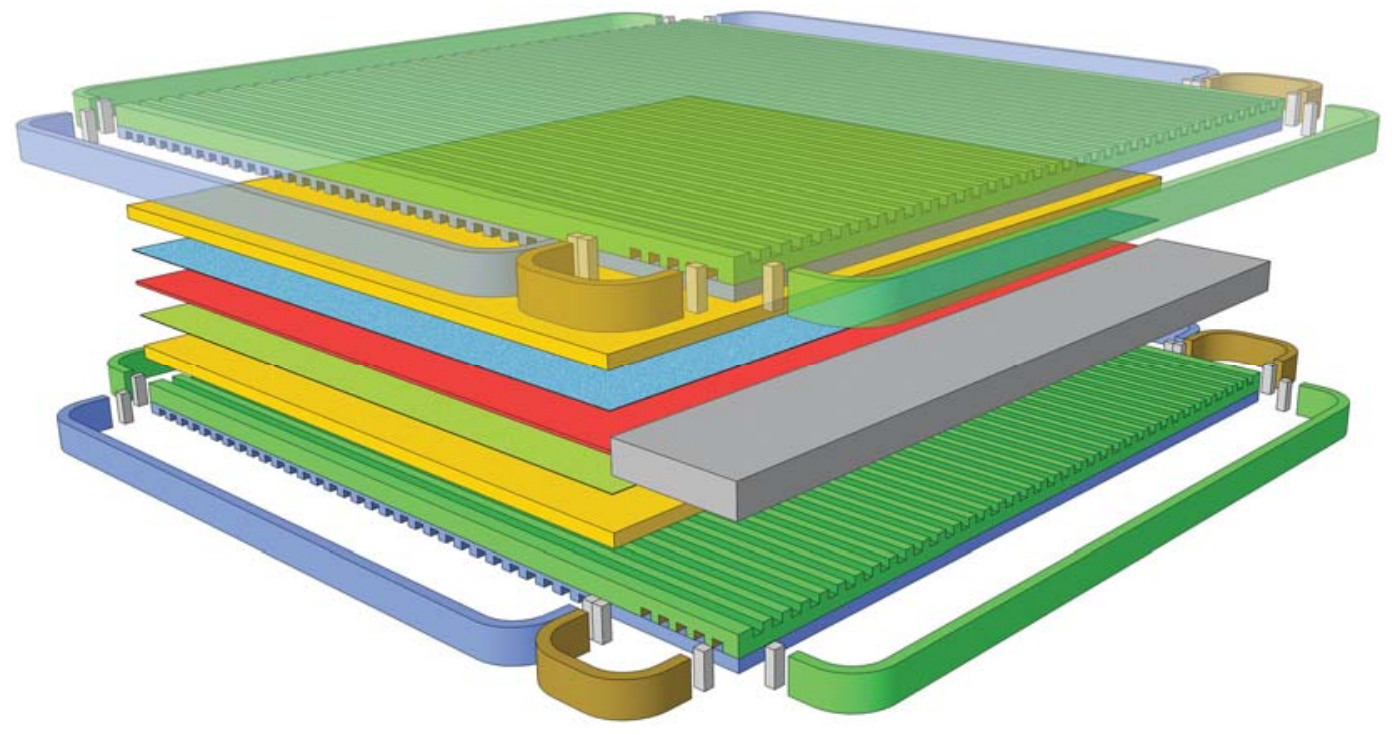

Figure 10. Alternative external-manifold planform with the coolant entering along one side. In this design the catalyst-coated membrane could have an edge-to-edge configuration.

Figure 9 shows a cell with a catalyst-coated membrane for an external manifold design with the corners removed to allow the coolant to enter and exit the bipolar plate. A seal would need to be established around the perimeter of the catalyst-coated membrane. The sealant would need to diffuse into the catalyst layer and not protrude above the layer to avoid stress when the cell stack is under compressive load. Applying a liquid seal that penetrates the catalyst layer in the sealing areas, but does not contaminate the active areas of the catalyst layer, can be a high-rate manufacturing problem. One approach is to deposit the seal using screen printing or ink jet printing. Hot pressing a thermoplastic seal or a thermoset seal at high rates may limit production rates because of the heating and cooling periods for the dies.

Figure 10 shows an alternative external-manifold planform with the coolant entering and exiting along one side. In this design the catalyst-coated membrane could have an edge-to-edge configuration. The seal material would be established around the perimeter of the catalystcoated membrane with a thicker seal region covering the coolant manifold region. The sealant must diffuse into the catalyst layer as described in Figure 9.

The height and durometer of the edge seal and the CCM must match to avoid the buildup of stresses at that interface. The technical issues are similar to those anticipated for the internal manifold system.

\section{External Manifold Manufacturing Approach 2: Selective Catalyst Deposition on the Membrane}

Selectively depositing the catalyst on the membrane is much simpler for the external manifold configuration than for the internal manifold configuration. This approach will require developing a high-resolution deposition process. Manufacturers may use screen printing, ink jet printing, and slot die tape casting to deposit the catalyst. A thin strip at the edges of the CCM needs to have a sealing zone (as shown in Figure 11). Matching the heights of the seal and the catalyst 
layer will still be necessary to avoid stress under compressive load. The thin-strip sealing zone of the CCM optimizes the use of the catalyst to $100 \%$.

\section{External Manifold Manufacturing Approach 3: Bonding the Catalyst-Coated Membrane to the Manifold}

This manufacturing approach is not viable because there are no large manifolds sections. All of the manifolds are external to the MEA.

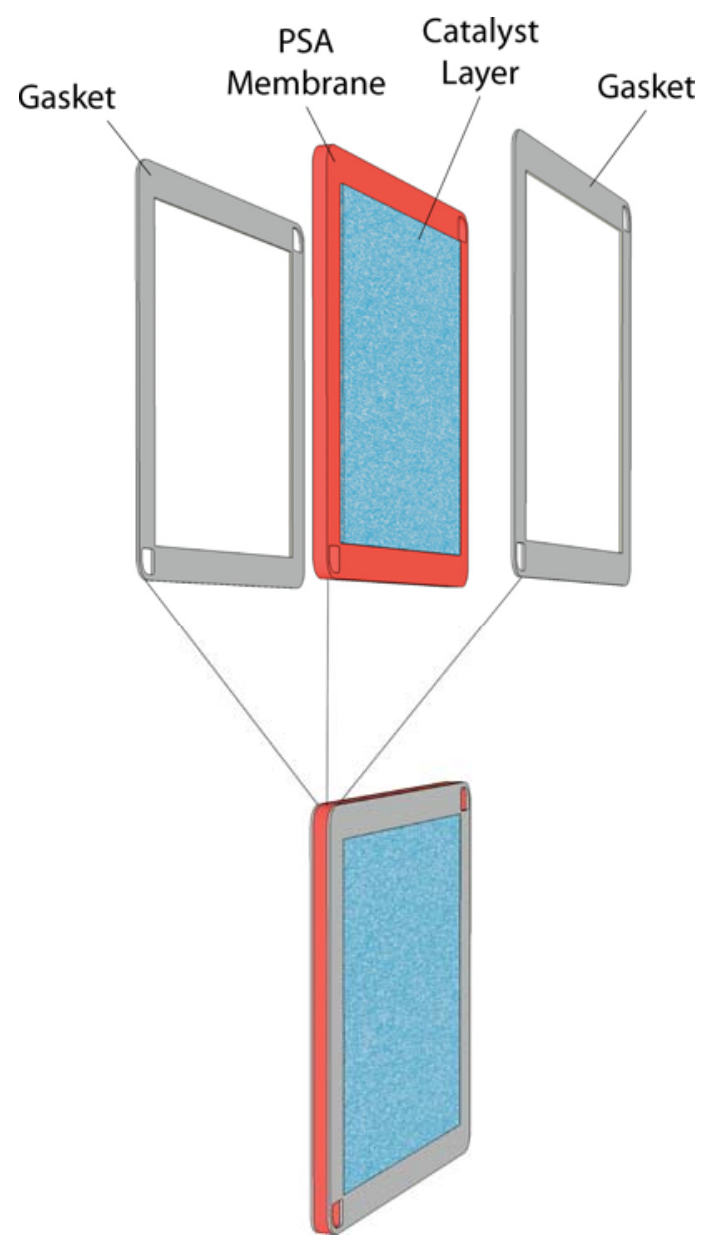

Figure 11. Thin-strip sealing zone of the CCM

\subsubsection{Cell Stacks with Mixed Internal and External Manifolds}

Figure 6 shows a theoretical mixed-cell planform with mixed internal and external manifolds. There are three approaches to manufacturing mixed internal and external manifolds.

Continuous catalyst coating of membrane

Selective catalyst deposition on membrane

Bonding the CCM to the manifold. 
Mixed Manifold Manufacturing Approach 1: Continuous Catalyst Coating of Membrane The continuous catalyst coating approach would consume excess catalyst, however it would not consume as much as the same process in an internal manifold system. The catalyst loss would be similar to the catalyst loss with all external manifold approaches; i.e., catalyst loss at the diagonal corners. Sealing issues would be similar to those discussed for the external manifold systems.

\section{Mixed Manifold Manufacturing Approach 2: Selective Catalyst Deposition on the Membrane}

The selective deposition process for a mixed manifold is similar to that of external manifold approach 2. This approach would require manufacturers to develop a deposition process and establish a sealing zone between the coolant ports and the active catalyst area. Matching the heights of the seal and the catalyst layer would still be necessary to avoid stress under compressive load.

\section{Mixed Manifold Manufacturing Approach 3: Bonding the Catalyst-Coated Membrane to the Manifold \\ Because the manifold for the coolant is small compared to the manifolds for the reactants this is not a beneficial manufacturing method.}

\subsection{Bipolar Plate Manufacturing}

Bipolar plates connect adjacent cells in the cell stack. One side of the bipolar plate is the anode preform for a cell while the other side is the cathode preform for the adjacent cell. Ideally, in operation the bipolar plates are electrically neutral; however internal resistance will develop a small potential across the bipolar plate. The plates have channels for directing the flow of reactants through the cells. Internal channels within the bipolar plates provide passages for the coolant. ${ }^{4}$ Figure 12 schematically represents the bipolar plates.

\subsubsection{Bipolar Plate Material Considerations}

Bipolar plate manufacturing is strongly influenced by the choice of construction materials. The material options for bipolar plates are

Graphite-resin polymer composite

Expanded graphite flake fabricated into a flexible graphite foil

Sheet metal.

The manufacturing processes for these materials are given in Table 2 .

\footnotetext{
${ }^{4} \mathrm{http}: / /$ www.fuelcellmarkets.com/fuel_cell_markets/bipolar_plates/4,1,1,2564.html
} 
Table 2. Bipolar plate manufacture concepts 5

\begin{tabular}{|l|l|l|}
\hline \multicolumn{1}{|c|}{ Material } & \multicolumn{1}{|c|}{ Processes } & \multicolumn{1}{c|}{$\begin{array}{c}\text { Material Process } \\
\text { Layout }\end{array}$} \\
\hline $\begin{array}{l}\text { Graphite-Resin Polymer } \\
\text { Composite }\end{array}$ & $\begin{array}{l}\text { Compression Molding, Injection } \\
\text { Molding, Polishing }\end{array}$ & Discrete \\
\hline Flexible Graphite Foil & $\begin{array}{l}\text { Expanded Flake, Rolling, Emboss } \\
\text { Impression (Compression) Molding }\end{array}$ & $\begin{array}{l}\text { Roll-to-Roll } \\
\text { Continuous graphite } \\
\text { foil fabrication; } \\
\text { discrete die cutting } \\
\text { step }\end{array}$ \\
\hline Sheet Metal & & Discrete \\
\hline
\end{tabular}

\subsubsection{Graphite-Based Bipolar Plates}

Graphite composite is prepared from graphite powder and a thermoset resin bonding agent. The composition is high in carbon, greater than $85 \%$, and preferably greater than $90 \%$ carbon. The high carbon solids content initially presented a hot pressing issue, however that issue has been solved by the developers.

Graphite-based bipolar plates are made in two pressing steps. A cathode bipolar plate preform is embossed with the flow-field pattern for the cathode reactant on one side and the coolant flow field on the other side. The anode bipolar plate preform is embossed with the anode flow field pattern on one side of the plate while the other side is left flat. The complete bipolar plate is assembled by bonding the flat side of the anode bipolar plate to the coolant flow side of the cathode bipolar plate. This is shown schematically in Figure 12. The manufacturing process used for the graphite-based plates requires that the preforms be parallel and flat to assure leakfree bonding and uniform electrical conductivity. In this example, the cathode bipolar plate preform was embossed on both sides, however it feasible to emboss the anode bipolar plate preform on both sides and have the cathode bipolar plate preform embossed on only one side with the opposite side flat.

An advantage of hot-pressing to a net-shape graphite bipolar plate is that the depth and uniformity of the flow field can be extremely consistent. The quality of the die used in the hotpressing operation will establish the depth and uniformity of the flow fields.

The manufacture of bipolar plates from graphite polymer composite is constrained by the time required to heat and cool the die used to press the preform plates. The thermoplastic resin used to bond the composite requires the die temperature to be below the resin curing temperature when the graphite polymer resin is injected into the die. The temperature is increased during the hot pressing step to set the resin. The die must be cooled prior to fabrication of the next preform plate. This temperature limitation is common for graphite-polymer composite plates, regardless of the manifold configuration.

\footnotetext{
${ }^{5}$ Source: Carlson, E.J., P. Kopf, P., Sinha, J., Sriramulu, S., and Yang, Y., Cost Analysis of PEM Fuel Cell Systems for Transportation, September 30, 2005, Subcontract Report NREL/SR-560-39104, December 2005
} 
The manufacture of graphite bipolar plates using thermoset resin does not require that the die be cooled. The cycle time is dependent on how long the thermoset resin takes to cure, which is based on the catalyst, the cross-liner molecule, and the thickness of the part.

The discrete nature of compression molding or injection molding used for graphite polymer composite manufacturing limits the production rate of any one press. As the demand for components increases, the number of hot-pressing stations will need to increase. The discrete nature and increased requirement for capital equipment will limit the potential cost reductions for graphite polymer composite bipolar plates.

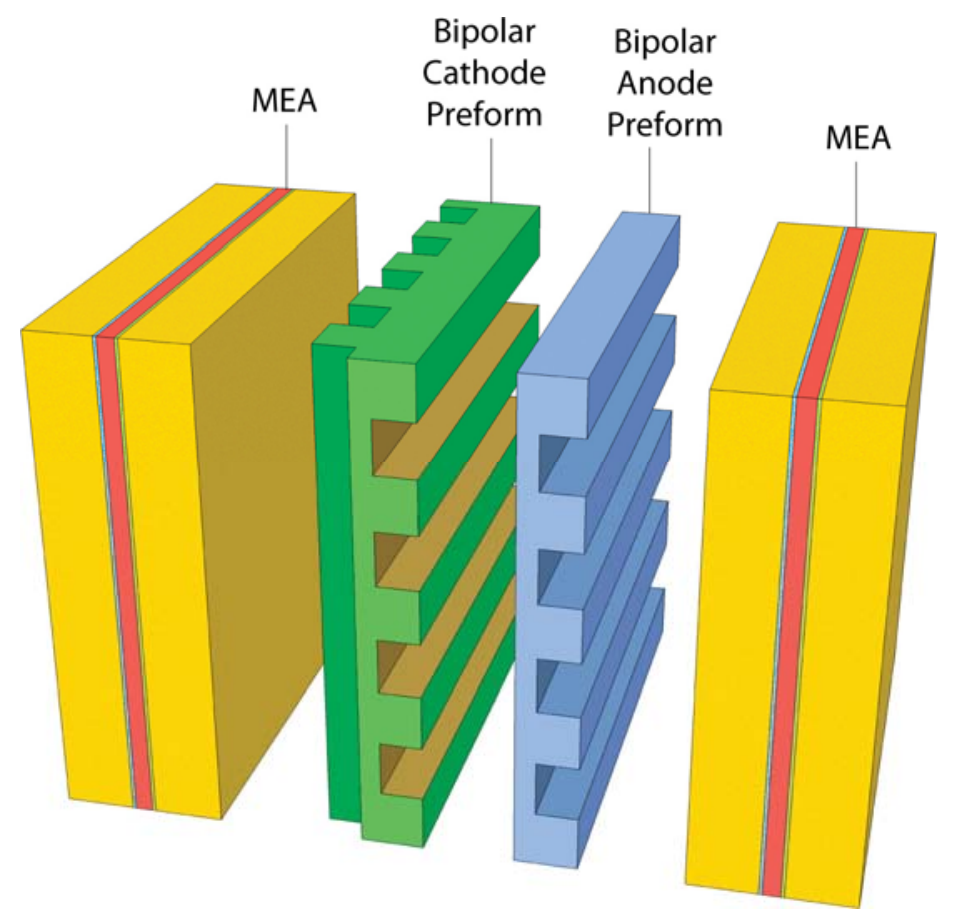

Figure 12. The complete bipolar plate is assembled by bonding the flat side of the anode bipolar plate to the coolant flow side of the cathode bipolar plate.

\subsubsection{Flexible Graphite Foil Bipolar Plates}

Flexible graphite foil is manufactured from natural expanded graphite flake and requires manufacturers to process the natural flake to form expanded graphite flakes. The expanded graphite flakes are roll processed to make a thin graphite foil. Graphite foil has high electrical conductivity, low contact resistance, and low specific density, and it can be readily manufactured using roll-to-roll continuous processes. The flow fields and seal patterns can be formed by emboss compression molding.

The embossed graphite foil is die cut into the individual bipolar plate preforms. The preform foil flows under compressive load and a thermoset resin, added prior to the foil production step, is used to give the bipolar plate preforms a rigid structure. The heat treatment stage to set the resin follows the die cutting step. 
Die cutting and emboss compression molding of the bipolar preforms are discrete processes. Continuous graphite foil manufacturing is interrupted by these discrete process steps.

Manufacturers will need to modify the emboss compression molding and die cutting processes to employ the continuous manufacturing capability.

\subsubsection{Sheet Metal Bipolar Plates}

Sheet metal bipolar plates are made by bonding two sheets of metal — each of which is pressed with the patterns for the reactant flow fields and the coolant. Stamping of three bipolar preforms is needed to include separate anode, cathode, and coolant flowfields. A bipolar plate fabricated from two preforms is possible as long as it is acceptable to have the coolant flowfield mirror (be the negative image of) one of the reactants. Welding the preforms together is an essential requirement to assure good electronic conductivity and controlled coolant flow patterns.

Researchers are developing alternative processing methods. Hydroforming is a new method under development and Figure 13 schematically shows the cross-section of a hydroformed bipolar plate. The flowfields all run in parallel for the hydroformed bipolar plate. The flow characteristics of the fuel cell will be restricted by this manufacturing approach to a combination of co-flow and counter flow.

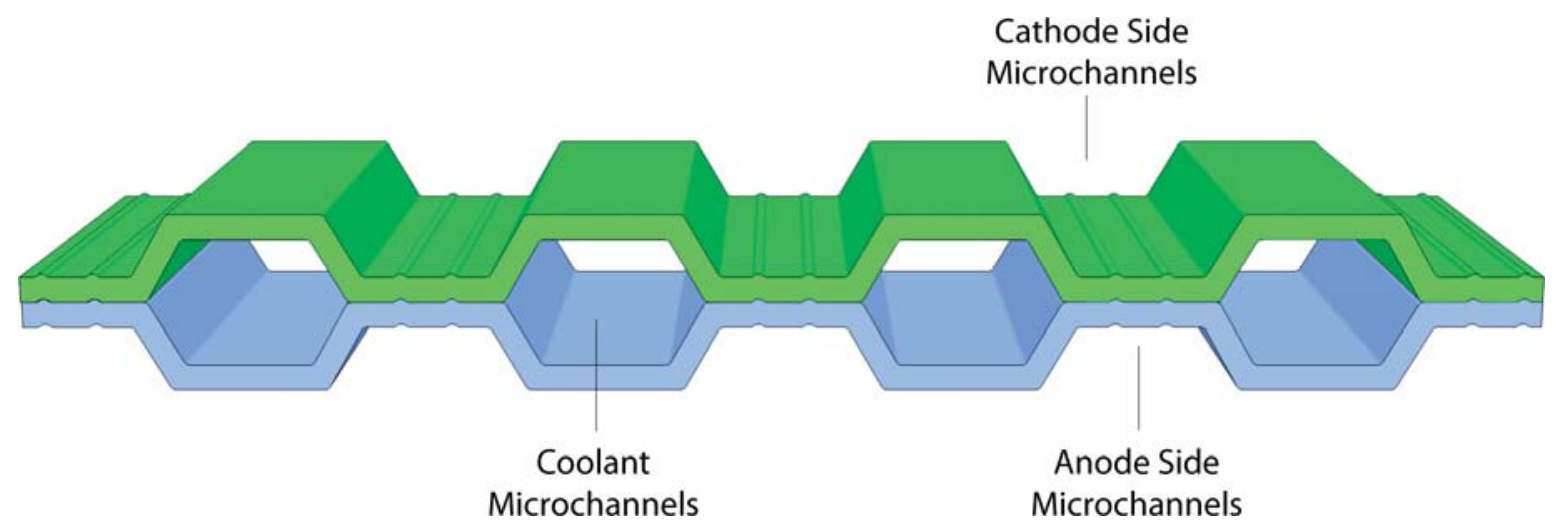

Figure 13. Cross section of metallic bipolar plate showing contacts to adjacent cells.

\subsubsection{Design Considerations for Bipolar Plate Manufacturing}

The design of the flow field and the design of the manifolds will influence the manufacturing approaches for the bipolar plates. The approaches to fabrication include:

Internal manifold bipolar plate fabrication using graphite foil and graphite-polymer composite

Internal manifold bipolar plate fabrication using sheet metal

External manifold bipolar plate fabrication using graphite polymer composite and flexible graphite foil

External manifold bipolar plate fabrication using sheet metal

Mixed internal and external manifolds using sheet metal. 


\subsubsection{Effect of Internal Manifold Designs on Bipolar Plate Manufacture Graphite polymer composite and flexible graphite foil}

The complexity of the bipolar plate for a cell stack with an internal manifold can be seen in Figure 5. The dies used to mold (compression or injection) the cathode and the anode preform will require precision design to assure proper alignment of the flow fields. Complex flow-field designs such as multi-channel serpentine flow fields and Z-channel flow fields as shown in Figure 5 have configurations with $180^{\circ}$ turns in the flow fields. The hot pressing and embossing molds for the complex flow fields require controlled release points for the dies that maintain the flow field configuration. The dies used in molding the internal manifold configuration bipolar plates must maintain the precise dimensions of the manifold to assure uniform distribution of reactants. Manufacturers will need to ensure that the preforms are both parallel and flat to assure the lowest possible electrical resistance in the bipolar plate.

Assembly and bonding of the preforms will require that the components are accurately aligned to assure that no edges impede the flow of reactants or coolant. The internal manifold design shown in Figure 14 identifies multiple edges within the manifold where misalignment would change the flow characteristics of the reactants to individual cells. Similar alignment requirements exist for the coolant internal manifolds to assure that the cell stack is cooled uniformly and hot cells are avoided.

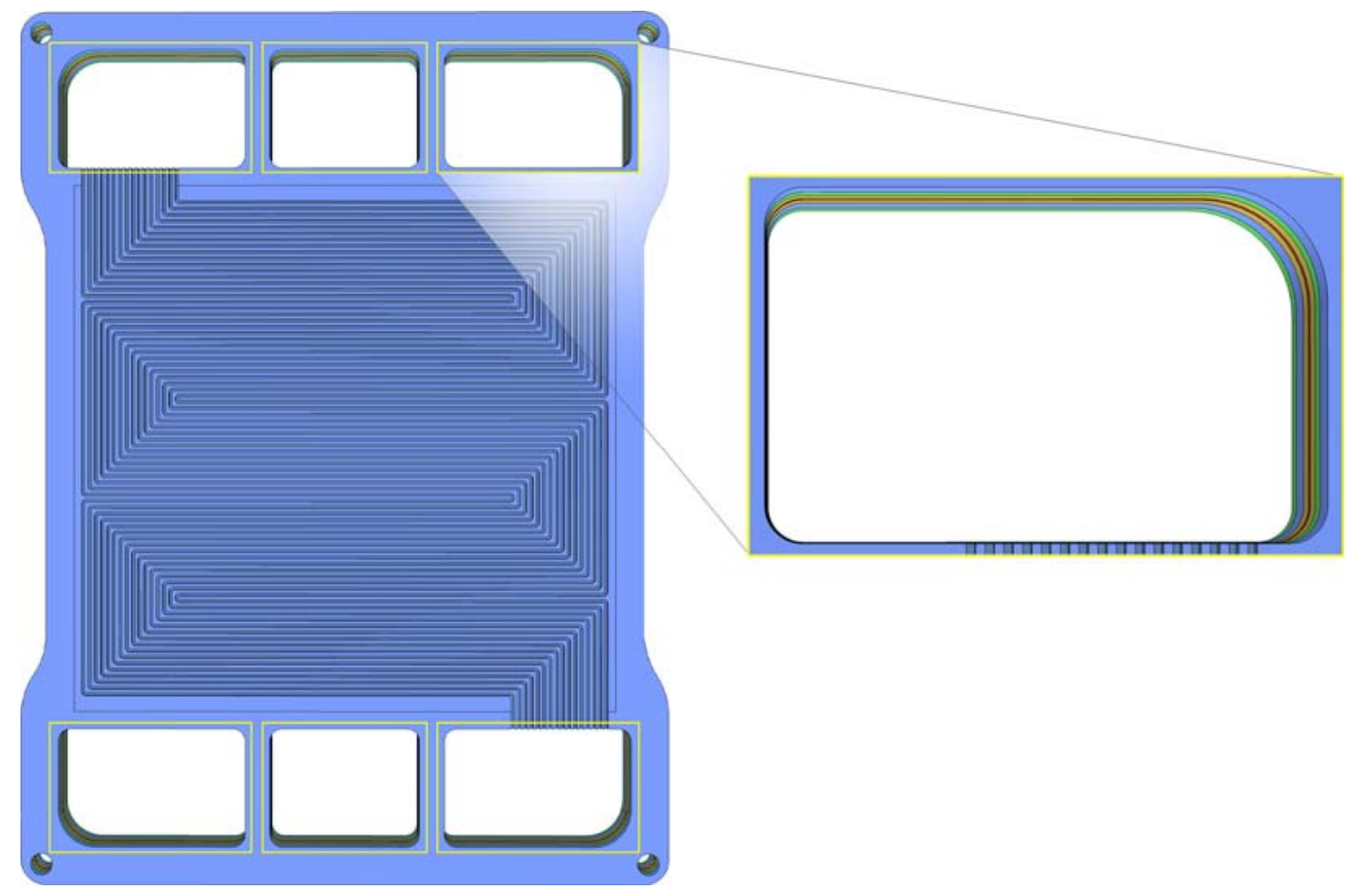

Figure 14. Schematic of cell misalignment in cell stack

\section{Sheet metal}

The design of the flow fields for the anode and cathode preforms will establish the flow patterns for the coolant. Welding the two preforms together at the edges does not assure good electrical conductivity in the center of the plates. Plates must be welded at the center to assure contact. 
The distribution and flow pattern of the coolant results in sheet metal plates with serpentine flow patterns or complex reactant cross-flow. The coolant-flow pattern is non-uniform and is the result of constructing the coolant flow field from the inverse of the anode flow field and the inverse of the cathode flow field. Using serpentine or cross-flow with sheet metal bipolar plates increases the possibility of uneven cooling of the cells.

\subsubsection{Effect of External Manifold Cell Stack Designs on Bipolar Plate Manufacturing Graphite-polymer composite and flexible graphite foil}

The external manifold design has fewer manufacturing barriers for the graphite-polymer composite and flexible graphite foil bipolar plates. This is because the design of the flow field is less complex, as shown in Figure 9 and Figure 10. Additionally, the embossing process can use a continuous roll rather than the individual embossing dies used in the external manifold system. The requirements of parallelism and flatness are the primary manufacturing issues. The process barriers associated with the materials and process steps for the graphite polymer composite and flexible graphite foil are the same.

\section{Sheet metal}

The design of external manifolds for co-flow and counter-flow bipolar plates is very difficult and has not been resolved. The complication of designing external manifolds restricts the use of sheet metal bipolar plates with external manifolds.

External manifold sheet metal bipolar plates operating in cross-flow will have the same issues as internal manifold sheet metal bipolar plates operating in cross-flow.

\subsubsection{Mixed Internal and External Manifolds}

Bipolar plates with mixed internal and external manifolds have manufacturing requirements similar to those described for each manifold design. The major manufacturing limitation for the graphite-polymer composite and flexible graphite foil bipolar plates is the complexity of the die that molds or embosses the flow fields and seal areas into the bipolar preforms. Preform parallelism and flatness must be rigorously maintained.

Two external manifolds and one single internal manifold are shown in Figure 6. Aligning the edges of the internal manifold (usually the coolant manifold) allows the coolant to flow to individual cells.

Sheet metal bipolar plates with mixed manifolds could be manufactured with one external manifold and two internal manifolds. Hydroforming the bipolar plates would have the benefits associated with internal manifold fabrications.

\subsection{PEM Fuel Cell Seals}

An $80 \mathrm{~kW}$ PEM cell stack has a large sealing area-if all the seals in an $80 \mathrm{~kW}$ PEM cell stack were laid out end to end, the seal length would approach one mile. Cell membranes are 50 micrometers thick and catalyst layers are 9 micrometers thick. The thinness of the components complicates the use of O-ring seals and picture frame seals. Matching the heights of the seals to the heights and diameter of the cell components is critical to maintaining good electrical contact between the bipolar plates and the MEA. Seals are designed to have height and compressive 
properties that assure the GDLs, the catalyst layers, and the membranes remain in contact for water/proton transport.

A primary issue is developing edge seals that prevent stress on the membrane when the cell stack is under compression. Designing an MEA with edge seals mitigates catalyst layer corrosion and premature failure of the MEA. Figure 15 illustrates the benefits of edge seals following the work at $3 \mathrm{M}$.

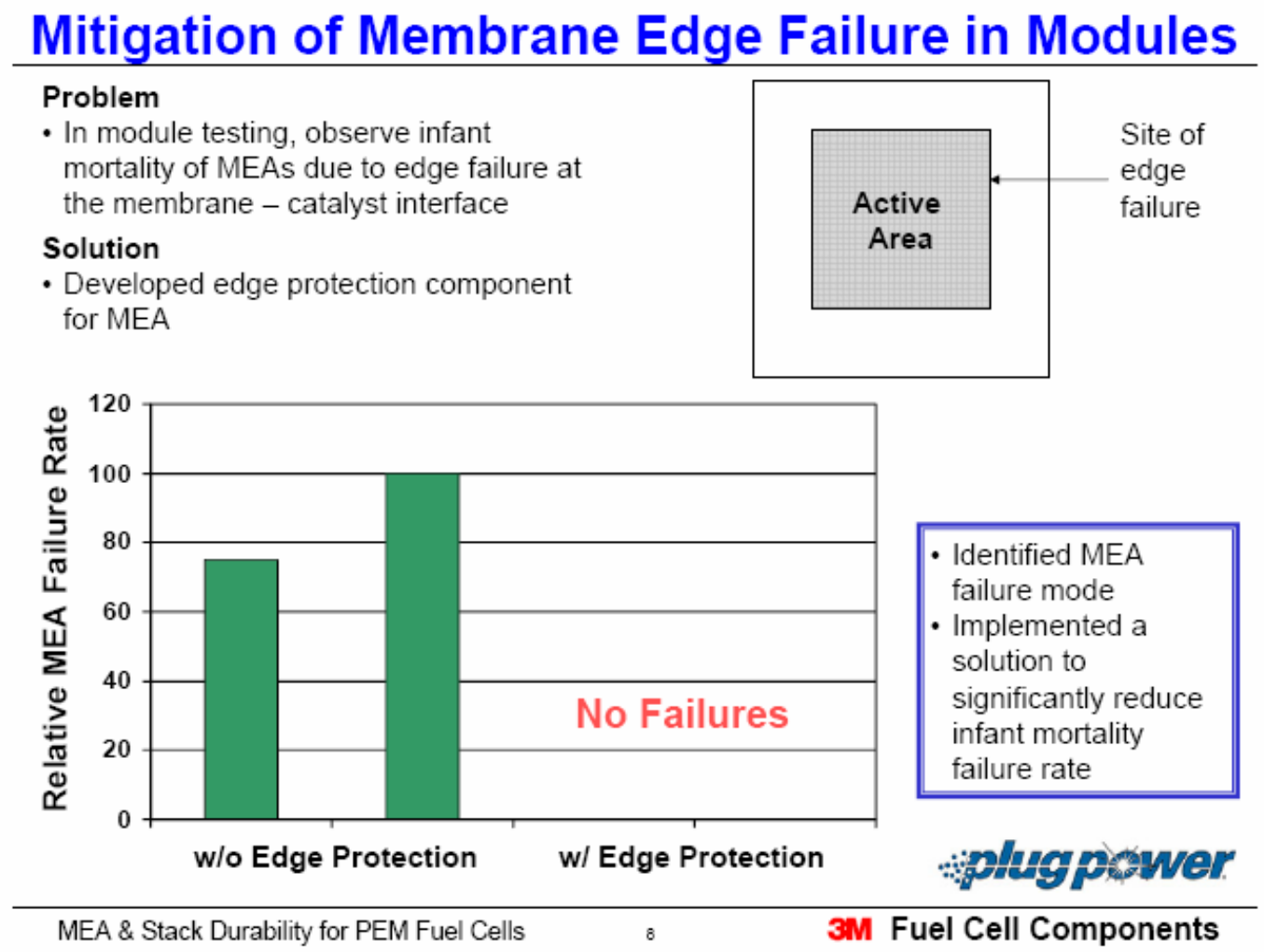

Figure 15: Edge seal protection ${ }^{6}$

Manufacturers need to develop high-rate edge seal application techniques similar to those used to deposit catalyst layers. These techniques might include spraying, screen printing, or ink jet printing the seals onto the MEA and bipolar plate components. Robotic application of sealing films that are 25 micrometers or less offers the prospect of high precision and repeatability.

\subsubsection{Design Considerations for Applying Seals to PEM Cells}

The design considerations for manufacturing seals for PEM cells are associated with the geometries of the areas that will require seal materials. A common problem will be maintaining the boundaries between the seal materials and the catalyst. Overlapping the seal material into the

\footnotetext{
${ }^{6}$ Hicks, M., "MEA \& Stack Durability for PEM Fuel Cells,” 2006 DOE Hydrogen Program Review, Project ID\# FC8, 3M/DOE Cooperative Agreement No. DE-FC36-03GO13098, 3M Company, May 16, 2006.
} 
manifolds, either internal or external, is a problem that must be eliminated, particularly for high rate production.

\subsubsection{Internal Manifold Design Considerations for Seals}

Comparing the sealing area in Figure 1 and Figure 2 shows the internal manifold has a greater sealing surface. It will be difficult for manufacturers to control the overlap of the seal material into the manifold regions because of the intricate nature of the internal manifold design.

\subsubsection{External Manifold Design Considerations for Seals}

The external manifold seal includes individual seals for bonding the cells as shown in Figure 3. Manufacturers need to develop a high-rate method for depositing sealing materials.

Additionally, a second seal is needed between the external manifolds and the cell stack. This seal is specific to the external manifold design.

\subsubsection{Extrusion of Seals into Manifolds}

Figure 16 highlights the extrusion of a seal into the manifold region of an internal manifold cell stack. The extrusion of seal material into the manifold can locally block the flow of reactants into the flow field. Fuel starvation along blocked flow fields can lead to carbon corrosion of the supported catalyst and failure of the cell and cell stack. Oxygen starvation at seal-blocked flow fields will lead to uneven current densities and low cell voltages. The extrusion of the seal into the manifolds will accelerate the failure of the PEM fuel cell.

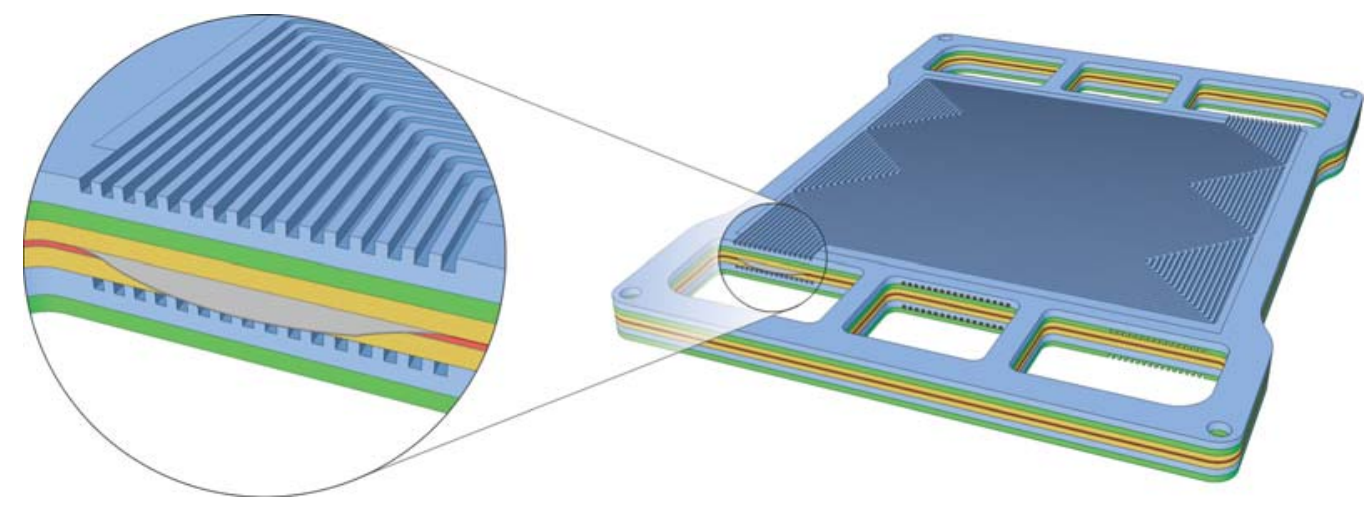

Figure 16. Design of the flow field in an internal manifold showing extrusion of seal

\subsubsection{Cell Stack Assembly}

The cell stack assembly has repeating components and non-repeating components. The MEAs, bipolar plates, and seals are repeating components. Non-repeating components are the end plates, tie rods, compression load system, and external manifolds. Assembling the repeating parts is a complicated and time-consuming process. Manufacturers must precisely align the repeating components to maintain stack durability and performance. The components must be properly aligned to reduce mechanical stress as the tear strength of the membrane is low and membrane failure is enhanced by mechanical stress. Figure 17 schematically shows the misalignment of cells in a cell stack and identifies stress points. The cell stacks are under compressive load to assure good electrical contact between adjacent cells and the contact between the MEA and bipolar plates. Manufacturers must evenly distribute the compressive load, which is partially controlled by specifying the flatness, parallelism, and thickness of cell components. 
The distribution of the reactant in the cell stack will be affected by the alignment of the individual cells in the stack. The performance of each cell is determined by the availability of the reactants. Cell misalignment will change the reactant flow characteristics in the manifolds. Restricting either reactant to a cell will decrease the voltage of the cell at the operating current density. The decrease in voltage lowers the efficiency of the cell and cell stack. Reactant starvation can occur for cells operating at high current densities, which would push the cell stack into a catastrophic failure.

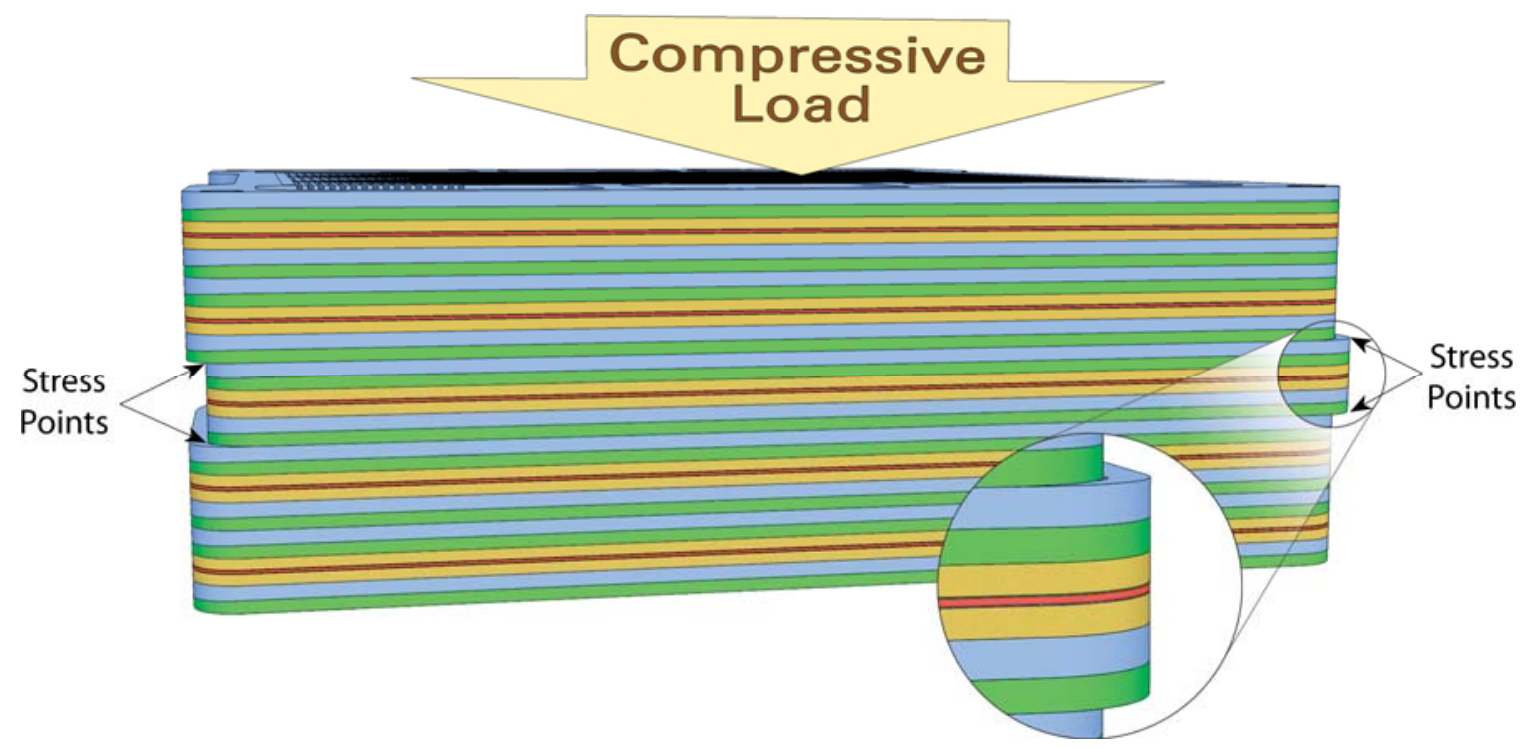

Figure 17. Seals are designed to have height and compressive properties that assure the GDLs, the catalyst layers, and the membranes remain in contact for water/proton transport.

\subsubsection{Design Considerations for the Assembly of Cell Stacks}

\subsubsection{External Manifold Design Effects on Cell Stack Assembly}

External manifold designs typically have small regions encapsulated by seals. However, the membrane area under the seal can have lower water content than the membrane in the active area of the electrode and stress can be induced at the edge seal/catalyst layer boundary. Aligning the cell components and controlling the water content of the membrane can relieve these stresses.

Cell misalignment produces stress points where the cells are misaligned. This is schematically shown in Figure 17.

Cell stacks with external manifolds have fewer edge seal/catalyst layer boundaries and the boundaries are typically at the perimeter of a cell. This reduces the regions for stress failure but does not eliminate the problem. Manufacturers must align the individual cells to eliminate the mechanical failure of the membranes. 


\subsubsection{Internal Manifold Design Effects on Cell Assembly}

Cells with internal manifolds have a large number of sites where misalignment can occur, including the edges of the internal manifolds. Each of these edge sites provides the opportunity for misalignment. These sites are identified in Figure 16.

The requirement to precisely align internal manifolds is much higher for the internal manifold designs because of the larger edge site boundaries. Internal manifold designs have larger areas where water does not have access to the membrane. The active area of the cell stack can be water saturated and the membrane thickness can change by as much as $15 \%$ in the thickness, or 7 microns; nearly $80 \%$ of the thickness of the catalyst layer. Much of the stress can be relieved through GDL compression. ${ }^{7}$ The stresses build up unevenly when the stack is under compressive load.

\subsection{Balance of Plant}

Balance of plant (BOP) refers to supporting and/or auxiliary components based on the power source or site-specific requirements and integrated into a comprehensive power system package. ${ }^{8}$ The BOP approaches discussed here are based on representative system designs but should not be considered all inclusive. Alternative, evolving system designs could require BOP components beyond the components and operating conditions described here. A common, universal BOP and system design has not been established for PEM fuel cells.

The components of the PEM fuel cell BOP will depend upon two major operating and design features:

\section{Reactant pressurization}

2. Water and thermal management.

Of the two BOP operating parameters, reactant pressurization has the greatest influence on the design and choice of BOP components. The water and thermal management approaches are modified depending on the reactant pressurization. Power conditioning was a third BOP design component that was identified by some of the companies that we interviewed. Other companies believed the power conditioning technology was sufficiently advanced that it could be readily adapted to satisfy the demands of PEM fuel cell systems.

\subsubsection{Pressurized PEM Fuel Cell System}

A schematic for a pressurized PEM fuel cell system ${ }^{9}$ is given in Figure 18 and shows the major components for the system. The expander-compressor is used to pressurize the air reactant. The system is designed to operate at variable pressure with high current densities at high pressures and low current densities at low pressures. This variable pressure operation attempts to

\footnotetext{
${ }^{7}$ Newman, J., Presentation on Investigating Failure in Polymer-Electrolyte Fuel Cells for the 2005 Hydrogen, Fuel Cells \& Infrastructure Technologies Program ..http://www.hydrogen.energy.gov/pdfs/review05/fc50 and Newman, J., Analysis/Characterization Subprogram from the Fuel Cells Session of the 2006 DOE Hydrogen Program Annual Merit Review, http://www.hydrogen.energy.gov/pdfs/review06/fc_29

${ }^{8} \mathrm{http}: / /$ www.nfcrc.uci.edu/fcresources/FCexplained/FC_Comp_BalanceOfPlant.htm

${ }^{9}$ Carlson, E.J., et al. IBID
} 
minimize the energy efficiency loss associated with pressurizing the air. Operating at low power with high air pressurization consumes excess energy and is a parasitic energy loss.

Differential pressure regulation across the anode and cathode is required to prevent high pressure differences from bursting the friable membrane. Controlling the differential pressure is essential and requires a fast and accurate response function for transient load operation. Figure 18 does not include the differential pressure regulator.

Conservation of energy is the primary goal of the BOP. The enthalpy wheel for this system provides for collection and recovery of a portion of the energy. The air from the electric motordriven expander-compressor is heated to temperatures greater than the PEM fuel cell can tolerate. On the other hand, the oxygen depleted air exiting the fuel cell is not hot enough to drive the expander-compressor. The enthalpy wheel provides a solution to the low-temperature spent air. The enthalpy wheel serves as an after-cooler/recuperator, humidifier, and a condenser. The enthalpy wheel transfers the heat from the compressed incoming air to the spent air from the cathode. The heated spent air assists in the operation of the expander compressor. The spent cathode exhaust is used to humidify and preheat the incoming hydrogen as shown in Figure 18.

An ejector is used on the fuel side to recycle the anode exhaust and mix a portion of the exhaust with the incoming, neat, hydrogen feed. Recycling the hydrogen in this manner increases the use of the hydrogen to nearly $90 \%$ and is energy efficient because the energy contained in the pressurized hydrogen feed is used to heat the incoming hydrogen.

At low current densities, the flow rate of hydrogen through the ejector is insufficient for hydrogen recycle. A hydrogen recycle pump is used to recirculate the hydrogen and to maintain high hydrogen use. 


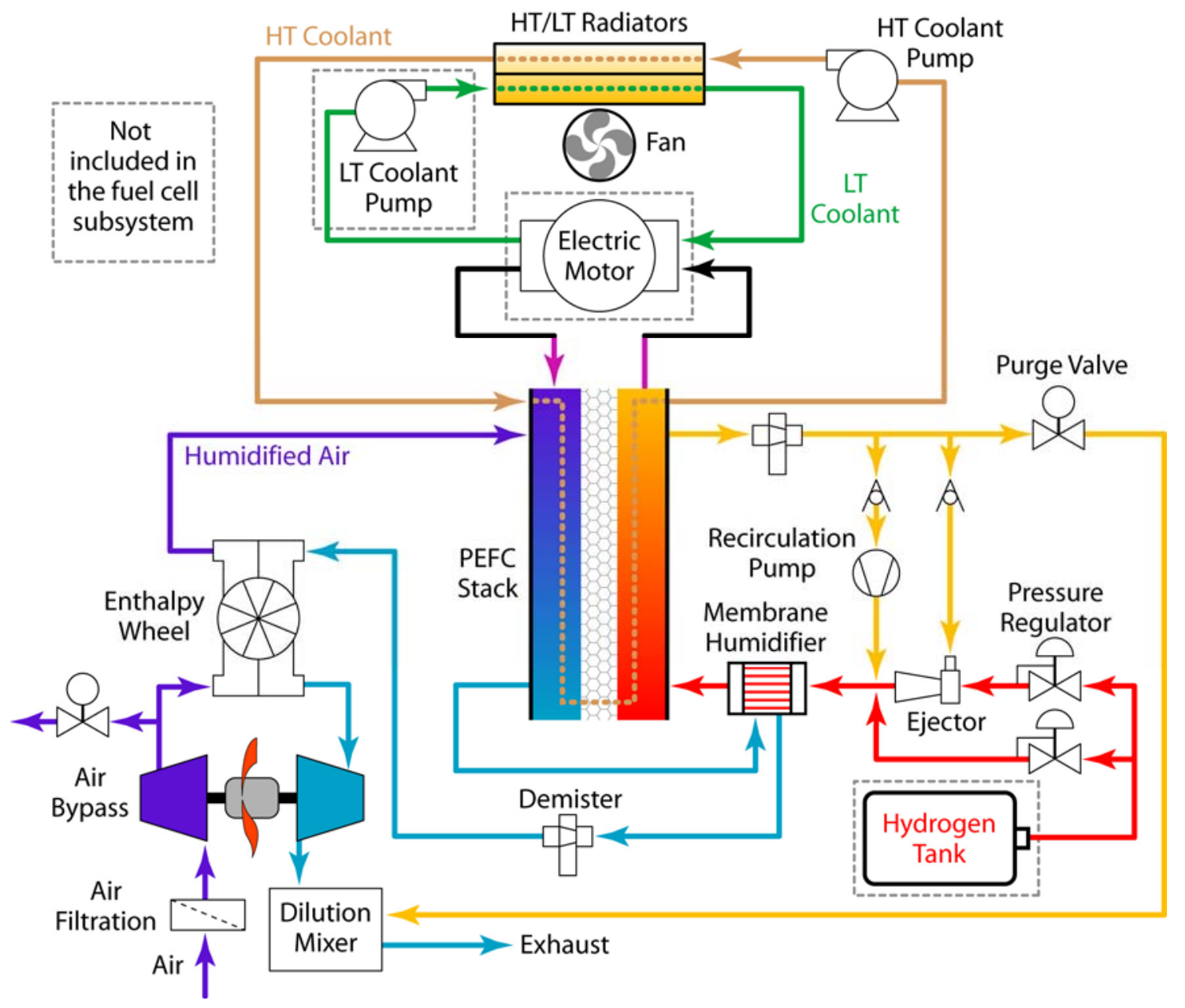

Figure 18: Schematic diagram of pressurized PEM fuel cell system

Recirculation humidifies the incoming hydrogen by mixing the saturated hydrogen exhaust with the incoming hydrogen. Additional hydrogen humidification is achieved using a membrane humidifier that transfers water from the spent cathode exhaust through a membrane to the incoming hydrogen. The pressure drop across the membrane humidifier must be controlled to prevent excessive mixing of the reactants.

The hydrogen flow manifold must be periodically purged to remove nitrogen and other inert gases that dilute the hydrogen concentration. The source of the nitrogen is crossover through the membrane from the cathode air side of the fuel cell. With hydrogen use approaching $90 \%$ through recycle, the nitrogen content of the anode gas builds up and can lower the partial pressure of hydrogen. Hydrogen starvation at the anode leads to catastrophic failure of the PEM fuel cell.

Thermal management of the pressurized PEM fuel cell is achieved using liquid coolant in a separate cooling loop. The coolant circulates through the individual cells and is cooled at the radiator. Manufacturers target a temperature difference of less than $10^{\circ} \mathrm{C}$ between the inlet and exit of the coolant in the cell stack. The narrow temperature range assures uniform distribution 
of the current within the cells. The narrow temperature range further maintains uniform water content in the membrane and increases the durability of the membrane.

A second coolant loop is used to cool the electric motor and electronics. The cell stack operates at temperatures greater than the electric motor and electronics and the cell stack temperature is controlled in the range of $60^{\circ} \mathrm{C}$ to $85^{\circ} \mathrm{C}$. The two cooling loops are shown in Figure 18 .

The low-temperature operation of the PEM cell stack compared to an internal combustion engine requires a larger radiator, greater coolant flow, and greater air flow. These differences create a technology gap for the PEM fuel cell.

\subsubsection{Atmospheric Operation of a PEM Fuel Cell}

Operating a PEM fuel cell at atmospheric pressure requires preheating the incoming air using the energy contained in the spent air from the cathode exhaust. A membrane humidifier uses the energy from the spent air to raise the temperature and concurrently humidify the incoming air as shown in Figure 19. This is the opposite of the pressurized system where the incoming air is cooled at the enthalpy wheel after the pressurization stage.

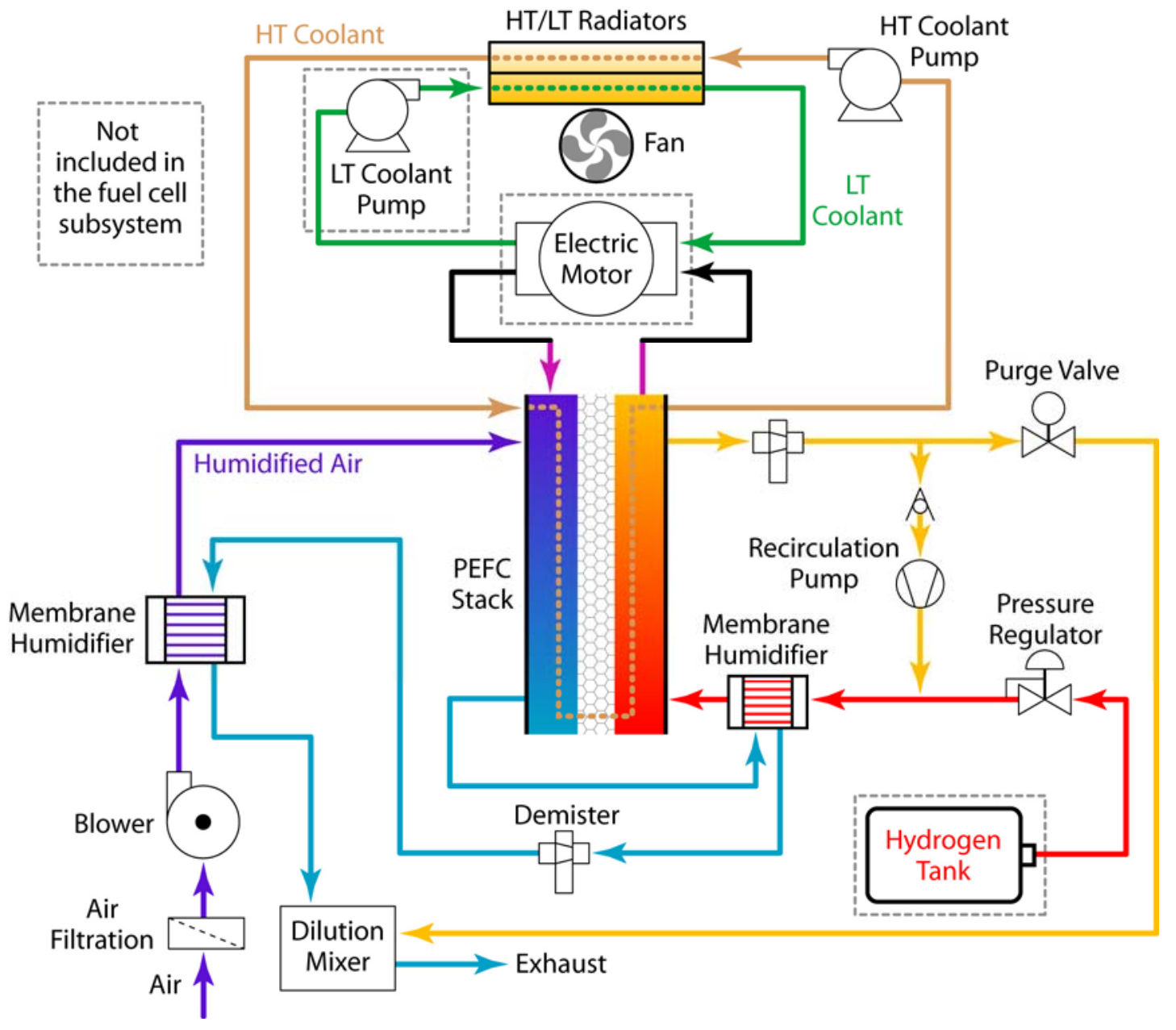

Figure 19. Alternative diagram of atmospheric PEM fuel cell system 
Periodic purging of the hydrogen is necessary just as it is in the pressurized system. The hydrogen is recycled using a recirculation pump. The ejector is not used for hydrogen recycle in the atmospheric pressure PEM cell stack. Differential pressure regulation between the fuel and air systems is not necessary since the system operates at atmospheric or near-atmospheric pressure over the complete power range. Operation at a single pressure is a major change from the pressurized system that operates at variable pressures. The single point pressure operation simplifies the BOP.

The atmospheric pressure cell stack operates in the temperature range of $60^{\circ} \mathrm{C}$ to $85^{\circ} \mathrm{C}$. Thermal management of the atmospheric PEM fuel cell stack is similar to the pressurized system. The narrow range for the temperature differential of the coolant inlet and exit remains the same at $10^{\circ} \mathrm{C}$. The design requirements for the thermal management system include larger radiators, high coolant flow, and high air flow over the radiator.

The differences in BOP design for pressurized and atmospheric PEM systems are summarized in Table 3.

Table 3. Comparison of BOP for pressurized design and atmospheric design PEM fuel cells

\begin{tabular}{|l|l|l|}
\hline \multicolumn{1}{|c|}{ Design Element } & \multicolumn{1}{|c|}{ Pressurized System } & \multicolumn{1}{c|}{ Atmospheric System } \\
\hline Air inlet & Cooled from compressor & Heated from blower \\
\hline Air inlet humidification & Enthalpy Wheel & Membrane humidifier \\
\hline Hydrogen inlet & $\begin{array}{l}\text { Ejector and recirculation pump } \\
\text { for } \mathrm{H}_{2} \text { recycle }\end{array}$ & Recirculation pump for $\mathrm{H}_{2}$ recycle \\
\hline Thermal management & $\begin{array}{l}\text { Two coolant loops: Cell stack, } \\
\text { high temperature loop at } 80^{\circ} \mathrm{C} \\
\text { to } 90^{\circ} \mathrm{C} \text { and lower temperature } \\
\text { cooling loop for electronics }\end{array}$ & $\begin{array}{l}\text { Two coolant loops: Cell stack and } \\
\text { electronics cooling loop. The cell } \\
\text { stack operates at } 60^{\circ} \mathrm{C} \text { to } 75^{\circ} \mathrm{C} . \text { A } \\
\text { larger radiator, higher coolant flow, } \\
\text { and higher air flow over radiator. }\end{array}$ \\
\hline
\end{tabular}

\subsubsection{BOP Differences Based on Thermal and Water Management Designs}

Three types of water and thermal management designs for PEM systems are considered:

Separate water management and organic coolant thermal management systems

Combined water/thermal management systems

Water management and air thermal management systems.

For small cell stacks, edge cooling is possible. The design of the cell stacks includes fins extending from the stack for edge cooling.

\subsubsection{Separate Water and Thermal Management Systems}

Separate water and thermal management systems maintain a cooling loop containing cooling fluid or antifreeze that is isolated from the cell stack. The organic coolants, such as propylene glycol, are separated from the cell stack to prevent contamination of the catalyst and poisoning of the electrochemical reactions. A separate reservoir for storing the coolant is included in the thermal management design. Thermal exchange at the radiator is controlled by the flow of 
coolant and flow of air over the radiator. The incoming hydrogen can be preheated by the membrane humidifier. Hydrogen recirculation assists in preheating and humidification functions. For the pressurized system, the hot air exiting the expander-compressor is cooled and humidified at the enthalpy wheel. Figure 19 shows the cell stack cooling loop and the cooling loop thermal management systems.

Water management is achieved using the enthalpy wheel on the air side and a membrane humidifier on the fuel size. The product water generated in the stack is removed by entrainment in the reactants. The product water is recovered and transferred to the incoming reactants using an enthalpy wheel and membrane humidifier. The enthalpy wheel and membrane humidifier serve two functions: (1) water recovery and humidification and (2) energy management.

For some designs, condensers (not shown in Figure 19) are used to reclaim the water from the cathode exhaust. A reservoir or accumulator stores a minimal amount of excess water for humidification at peak power operation in low humidity environments and for fuel-cell start-up.

\subsubsection{Combined Water/Thermal Management System}

A combined water/thermal management system is used in the PEM cell stacks developed by UTC Power, Inc. (UTC). The cooling loop contains water that communicates to the cell stack through porous bipolar plates. The water is held in the porous plates by capillary pressure and the pore size distribution of the porous plates is designed to facilitate the retention of liquid water. The cell pressure is slightly higher in the cell stack than the coolant chamber and the pressure differential promotes the transfer of water from the cell to the coolant loop. The porous bipolar plates have four functions:

Humidification and preheating of the incoming reactants

Removal of product water from the cell stack

Cooling or heating of the cell

Separation of the reactants in adjacent cells.

The BOP of the UTC design differs from the PEM system with separate thermal and water management systems. High-purity water makes up the cooling loop, which includes an ion exchange resin to remove foreign metal ions that could poison the cell-stack catalyst. The cooling loop serves as a reservoir for humidification water. One coolant pump is required and the system typically operates near atmospheric pressure.

\section{Humidification and preheating}

The incoming reactants are humidified at the inlet to the cells with evaporation of the water contained in the porous plates. The design is beneficial to the membrane system since the porous plates provide humidification water to the incoming air and water loss from the membrane is eliminated. Catastrophic failure for the PEM fuel cells can occur when the membrane dries out. Hydrogen recirculation provides energy and humidity exchange for the incoming hydrogen. In some designs a membrane humidifier or energy-exchange barrier could be used to preheat and humidify the incoming hydrogen. 
Although not required, an enthalpy exchange barrier ${ }^{10}$ provides for conservation of energy for the oxidant. The enthalpy exchange barrier replaces the membrane humidifier with a wettable fine-pore structure that transports energy and water vapor to the incoming air

\section{Removal of product water}

The product water generated at the cathode transfers to the porous bipolar plates through capillary action with assistance from a small pressure differential between the reactants and the coolant; approximately four inches of water per square inch. Excess water collected in the cooling loop is purged from the system.

\section{Cooling or heating the cell stack}

The porous bipolar plates conduct heat from the cell stack to the coolant (similar to the designs with separate water and thermal management systems). In addition, the temperature of the cell stack is controlled by transport of the product water to the coolant. Within the cell, the temperature is maintained through water evaporation from the bipolar plate or water condensation in the porous bipolar plates.

\section{Separation of reactants}

The coolant water filling the pores of the bipolar plates is a barrier to mixing the reactants in adjacent cells. The mixing that does occur is governed by the solubility of the reactants in water.

\subsubsection{Water Management and Air Thermal Management Systems}

Manufacturers have built PEM fuel cell systems with air thermal management for smaller PEM fuel cell systems; e.g., a portable fuel cell to replace the BA-5590 battery used by the U.S. military. By using air cooling they can reduce the number of BOP components in the system and integrate the cell design and radiator. The air is moved over the cells by thermal convection or a fan depending on the application. For small cell stacks, edge cooling is possible. The design of the cell stacks includes fins extending from the stack for edge cooling.

The cell stack for an air-cooled system is larger than for liquid-cooled systems. Channels between cells provide the pathways for removing heat from the cell. Cell stacks with designs similar to heat exchangers and fabricated from thermally conductive metals fulfill many of the requirements for air-cooled PEM systems. Internal manifolds are used to deliver the reactants and the internal manifold design affords cooling channels adjacent to each cell component.

Air cooling is used with portable systems where weight is critical. Small fuel-cell systems with power ratings of less than 100 watts, such as direct methanol fuel cells for portable applications, operate well with air-cooling systems. Larger ( $1 \mathrm{~kW}$ to $5 \mathrm{~kW})$ air-cooled PEM fuel cell stacks are offered by Ballard for backup power applications. The system integrator must develop the BOP components for these stacks.

\subsubsection{Power Conditioning Design Considerations}

The power conditioning design will establish the power conditioner specifications. In Table 4 power conditioning applications are identified with the corresponding design characteristics. Developing power conditioning units will depend upon the volume of the business opportunity.

\footnotetext{
${ }^{10}$ U.S. Patent No. $6,475,652$
} 
For remote power applications and backup power applications, industry reports that the cost of the power conditioning units is very high. Our industrial contacts believe that the cost can and will be driven down as the demand for remote power and backup power increases. Higher demand will increase investment in power conditioning units.

Table 4. Power conditioning and applications

\begin{tabular}{|l|l|}
\hline \multicolumn{1}{|c|}{ Application } & \multicolumn{1}{c|}{ Power Conditioner Design } \\
\hline Portable Power & Regulated DC Power: <100 Watts; 48V \\
Remote Power & Regulated AC Power 2kW - 8kW; 220 V \\
Backup Power & Regulated DC Power 5kW; 28V - 48V \\
Military Propulsion / Sensors & Regulated DC Power 500W - 10kW; 28V-48V \\
Stationary Power & Regulated AC Power: 200kW-1000kW; 440V \\
APU & Regulated DC Power 1kW -4kW; 28V - 48V \\
Transportation (light vehicles) & Regulated DC Power $80 \mathrm{~kW} \mathrm{300V}$ \\
\hline
\end{tabular}

Power requirements and voltage requirements vary depending on the application. There is some overlap in power conditioning requirements. Our industry contacts do not believe there is a technical barrier to manufacturing power conditioning units. 


\section{Status of Manufacturing and Gaps in Manufacturing Technologies for PEM Fuel Cells}

The challenge of moving from low-volume, high-quality, high-cost production to high-volume, high-quality, low-cost production was successfully addressed by the electronics, agriculture, plastics/chemical, and automobile industries in the $20^{\text {th }}$ century. PEM fuel cell stack components are under development and presently fit in the low-volume, high-quality, high-cost category.

The production rates required to fulfill automobile requirements are very high. Light-vehicle production for the United States in 1999 was over 12 million. ${ }^{11}$ Using the DOE's recommended production reference for mass production at a plant of 500,000 vehicles per year, manufacturers would need to build a fuel cell stack every minute (assuming 365 working days per year and three shifts operation). With 400 cells per stack and 800 bipolar plate sets (two bipolar plates per plate set), producing a fuel cell stack will require various types of assembly equipment operating at high rates.

The MEA is the heart of the fuel cell and is unique to the PEM fuel cell. The MEA accounts for the greatest number of parts within the fuel cell stack. The MEA components for large scale production are the membrane, the catalyst layers, and the gas diffusion layers. The bipolar plates in the PEM cell are the final large volume component for the PEM fuel cell.

We define a production technology gap as the lack of manufacturing processes to produce highvolume, high-quality, low-cost product. General production gaps for the PEM fuel cell include:

- Manufacture of MEA components

- Assembling the MEA and bipolar plates into a cell stack

- Sealing the MEA into a unitized structure and bonding the MEA to the bipolar plates

- Applying quality control techniques and manufacturing tools (see Appendix A) to the production of the MEA, bipolar plates, seals, and stack assembly. The quality measurement and control methods will need to be adapted for high production rates for all of the cell stack components and for the assembly of the cell stack. The need for quality control is underscored by the need for a series electrical connection of the individual cells in the stack. With over 400 cells per stack, the Six Sigma criterion would anticipate $1 \%$ failure of the stacks.

\subsection{Manufacturing Gaps for 3-Layer MEAs}

Roll-to-roll processing of multilayer films is a well established production technology. Over \$26 billion of unsupported plastic films are produced and shipped yearly, based on 2001 data, while laminated and coated products make up an additional $\$ 1.5$ billion a year in shipments. ${ }^{12}$ The polymeric film industry is mature and production capacity is measured in tons of film produced.

\footnotetext{
${ }^{11}$ Light Vehicle production: Infoplease, http://www.infoplease.com/ipa/A0104789.html

${ }^{12}$ U.S. Department of Commerce, http://www.ita.doc.gov/TD/Industry/OTEA/industry_sector/tables_naics.htm
} 


\subsubsection{Production Gaps for Membranes}

The gap for membrane production is production capacity, which is limited by low demand. North American and Japanese industry have established techniques for applying film processing methods to perfluorinated sulfonic acid (PSA) membrane production. Nafion, Flemion, Aciplex, and Gore membranes are fabricated using roll processing methods. Other emerging membrane technologies such as Arkema's PVDF-based membrane and 3M membranes are grounded on well-established roll processing manufacturing processes. These companies report that the transition to large scale production of PSA and alternative membranes will be possible without a manufacturing process research and development activity. MEA manufacturers identified a need to develop in-line quality control processes to identify specifications for membrane thickness and chemical composition.

\subsubsection{Production Gaps for Depositing Catalyst onto Membranes}

Methods for depositing catalyst onto a membrane to form a three-layered structure compatible with PEM fuel cell design constitute a manufacturing process gap. Several companies have developed processes for limited production of catalyst-coated membranes using a batch mode. These companies are capable of producing 1000 catalyst-coated membranes per line per day.

W. L. Gore and 3M report successful deposition of catalyst layers to fully coat a membrane, i.e. edge to edge coating, using roll-to-roll processing. However, 3M reports for a specific type of MEA that edge to edge coating leads to premature failure of the membrane and suggests that catalyst layers on the membrane should have a picture frame configuration as shown in Figure 15. 3M concluded for the MEA design under consideration that MEA failure could be reduced and possibly eliminated by a picture frame configuration. It has not been proven that the picture frame configuration will improve the stability of all MEA designs and configurations. Methods for depositing the catalyst layer onto the membrane include the following:

- Screen printing

- Ink jet printing

- Aerosol deposition

- Painting

- Doctor blade coating

- Slot die coating.

- Gravure printing

Manufacturers can apply the catalyst layer by either direct deposition onto the membrane, decal transfer using an inert film base such as polyester, or deposition onto a GDL to form a GDE.

Barriers to the deposition processes are:

- Direct coating the catalyst onto the membrane requires the use of water-based inks or paints. The evaporation of the water from the catalyst layer needs to be controlled to assure that water in the membrane is not lost. Organic solvents absorb into the membrane and can contaminate the membrane and the catalyst layer. 
- Changes in the membrane volume during direct coating are a barrier to production. The addition of solvent into the membrane during direct coating can swell the membrane. Subsequent evaporation of the solvent from the membrane will shrink the membrane and the interface between the membrane and the catalyst layer becomes stressed and delaminating of the catalyst layer from the membrane is possible.

- Direct coating of the catalyst onto a PSA membrane that is fully hydrated is difficult because of the low tear strength of the PSA. However, reinforced PSA membranes are stronger and catalyst layers can be deposited on the hydrated, reinforced PSA membrane.

- The direct deposition of catalyst onto dry PSA membrane is possible because the dry PSA membrane has greater tear strength. The catalyst layer can be deformed during hydration due to membrane swelling. This can induce in-plane compression of the catalyst layer.

- The decal transfer method eliminates the issues with organic solvents since the catalyst layer is deposited on an inert substrate that can be heated to remove the solvents. The gap for the decal transfer method is the additional step required for transferring the catalyst to the membrane.

The decal transfer method can be used with a fully hydrated membrane.

- Deposition of the catalyst layer onto the GDL requires an additional layer (the microlayer) that interfaces between the catalyst layer and the GDL. The microlayer compensates for the uneven texture of the GDL. The microlayer is typically hydrophobic, and catalyst deposition using aqueous solvents is difficult and presents a potential barrier.

- Bonding of the catalyst layer to the GDL requires a hot pressing step to insure intimate and permanent contact between the catalyst layer and the microlayer/GDL.

\section{Gap \#1}

A manufacturing gap is the manufacturers' inability to deposit catalyst layers at high rates on a planform where the catalyst layer does not fully cover the membrane (e.g., edge seals at the manifold connections). The registration of the framed catalyst layers is an issue requiring resolution for high rate manufacturing. 3M reports progress in this area with their recent patent U.S. 7,195,690. Their proposed roll processing production process is shown in Figure 20, which is taken from U.S. 7,195,690. 


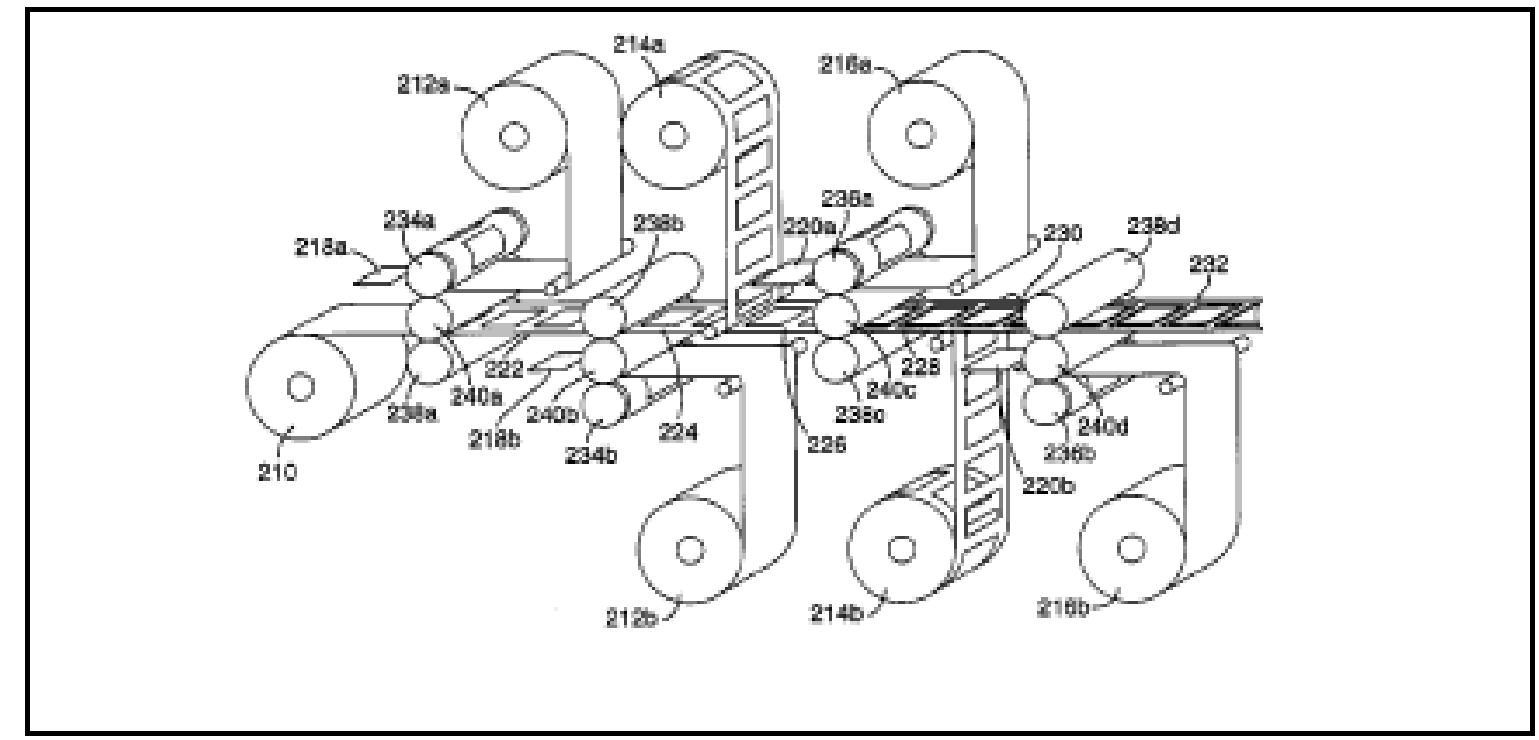

Figure 20: Roll processing process for depositing catalyst layers formed with edge seals using the decal transfer method; from 3M patent U.S. 7,195,690.

Manufacturing research and development are needed to adapt roll processing technology to fabricate catalyst-coated membranes with configurations consistent with fuel cell designs. Coatema is one company that has commercial equipment for roll processing catalyst-coated membranes.

\section{Gap \#2}

A manufacturing gap exists in controlling the thickness and conformity of the catalyst layers as they are deposited on the membranes. Lack of registration and misalignment can produce stress on the fragile PSA membrane when assembled in a stack and placed under compressive load.

Manufacturers need to develop techniques for measuring the alignment of the catalyst layers, the thickness of the catalyst layers, and the distribution of precious metal catalyst under high rate production conditions. They will need to correlate these parameters with durability and performance.

\subsubsection{Low Loading Catalyst Layers}

\section{Gap\#3}

A manufacturing gap exists for deposition of low loading catalyst layers. This gap is reported separately from Gap \#2 and includes the deposition of low catalyst loadings onto support materials and the direct deposition of the catalyst onto the membrane or microlayer of the GDL. The low catalyst loading is associated with very thin catalyst layers. The thin catalyst layer will require manufacturers to develop new manufacturing methods for CCMs and GDEs. Physical deposition methods similar to those used by the semiconductor industry will need to be adapted to roll processing manufacturing of PEM fuel cells for CCMs with low catalyst loadings or GDEs with low catalyst loadings. 3M reports vapor deposition of catalyst onto pigment; and 3M uses the decal method to transfer the catalyzed pigment layer onto the membrane (see Figure 20). 
Manufacturers will need to develop quality measurement and control capabilities consistent with the deposition of very thin layers. Measurement techniques similar to those developed for semiconductor manufacture may have to be employed. These will need to be integrated with the production processes for low loading catalyst layers.

\subsection{Manufacturing Gaps for 5-layer MEAs}

\section{Gap\#4}

Depositing catalyst onto a GDL in a way that is compatible with the PEM fuel cell design is a manufacturing gap. E-TEK reports successfully depositing catalyst onto GDLs to form GDEs using roll processing methods. This E-TEK approach is an alternative to the catalyst deposition processes discussed in the previous section, and the manufacturing gap is similar to that for catalyst layer deposition. Deposition of the catalyst layer onto the GDL when the catalyst layer does not fully coat the GDL is a manufacturing gap. Manufacturing research and development is needed to adapt roll processing technology to fabricate catalyst-coated GDLs with configurations consistent with fuel cell designs.

\section{Gap \#5}

A manufacturing gap exists for controlling the quality of the catalyst layer deposited on GDLs. The thickness and catalyst distribution of the catalyst layer need to be measured during the production of the GDE. Manufacturers need to establish ways to correlate the production characteristics of the catalyst layer in the GDE with durability and performance.

SGL reports that it has successfully produced GDLs at high rates. In its process, a micro-layer is deposited on the GDL prior to catalyst deposition. SGL offers several types of micro-layers and GDLs produced using roll-to-roll processing. There does not appear to be a gap in the manufacturing process for high-speed production of GDLs.

\section{Gap \#6}

There is a manufacturing gap in the high-rate production of 5-layer or greater MEAs. Applying GDLs to the 3-layer catalyst coated membrane in an integrated assembly line is a manufacturing gap. Registration of the layers with a framed configuration is an issue that will need resolution. Manufacturers will need to develop processes to adapt laminated film and packaging manufacturing methods to high-rate production of 5-layer MEAs. Coatema, for example, has commercial roll processing equipment available for manufacturing MEAs.

\section{Gap \#7}

Registration of the catalyst layers onto the membrane is a critical feature. The catalyst layers contain PSA ionomer that is added as a dilute liquid. Heat treatment is needed to cure the ionomer and stabilize the ionomer to prevent dissolution during fuel cell operation. The heat treatment processes is hot pressing, which can take up to 90 seconds. This is a bottleneck to the production of the 5-layer MEAs. The hot pressing step is used in both the CCM approach and the GDE approach.

Controlled cooling of the hot pressed layer is necessary to assure that heat stresses to the membrane are eliminated. 
Integrating the bonding of the GDLs to the CCM with the hot pressing step does not eliminate this bottleneck in production. The 90 second hot pressing limits production to 40 MEAs per hour per hot press. The development of a continuous hot roll pressing procedure is needed to eliminate this bottleneck. Stratum Industries reports continuous hot roll pressing is possible; however they had not applied the hot roll pressing to MEA production.

Manufacturers will need to develop and integrate quality measurement and control methodology with the high rate, multi-layer production processes.

\subsection{Manufacturing Gaps for Bipolar Plates 3.3.1 Carbon Bipolar Plate Manufacture}

\section{Gap \#8}

There exists a manufacturing gap for the high-rate processing of carbon-based bipolar plates. Two types of carbon-based bipolar plates have emerged for PEM fuel cells: resin bonded graphite powders and expanded natural graphite. Large volume manufacturing has not been established for either material. A manufacturing limitation for both materials is the need for heat treatment to set the thermal resin that maintains the shape and configuration of the bipolar plate. DANA Corp. has identified the need for manufacturing R\&D to optimize the thermal control and hot pressing of resin bonded graphite powders. GrafTech International, LTD, indicated that embossing of the continuously manufactured graphite was possible. The limiting process step appears to be die cutting the expanded graphite to a bipolar plate configuration and subsequent heat treatment to set thermal resin.

\section{Gap \#9}

A manufacturing gap exists in quality control of the bipolar plate fabrication. The flatness and parallelism of opposite faces of the bipolar plate are critical. The depth and uniformity of the flow fields need to be maintained within specification to assure proper distribution of reactants. Early work by the National Renewable Energy Laboratory and Plug Power confirms a correlation of these parameters to bipolar plate performance.

\subsubsection{Metal Bipolar Plate Manufacture}

\section{Gap \#10}

Treatment of the metallic bipolar plates to maintain conductivity and passivity of the metal is a manufacturing gap. Metal bipolar plates that have protective surfaces require heat treatment to develop the protective coating. The heat treatment can be as long as 10 hours and manufacturers will need to adapt existing heat treatment processes to assure uniform, controlled heating so the metallic bipolar plate does not deform.

Passive stainless steel bipolar plates with conductive inclusions, such as those described in Sumitomo patent U.S. 6,379,479, require chemical treatment such as acid leaching to expose the conductive particles with subsequent acid neutralization to eliminate further corrosion of the passive layer. Heat treating the metal with slow controlled cool down permits the development/dispersion of carbide particles within the metal. The processes used are well 
established manufacturing methods but manufacturers will need to adapt them for high-rate production.

\section{Gap \#11}

Multiple flow field designs; reactant flow fields and coolant flow field, in cross-flow, serpentine or Z-flow configurations will require the welding of multiple metal preforms to form a single bipolar plate.

Manufacturers will need to develop quality measurement and control methodologies to assure flatness and parallelism of the metallic bipolar plates. The depth and uniformity of the flow fields need to be maintained within specification to assure that the reactants are properly distributed.

\subsection{Manufacturing Gaps in Seal Application for MEAs, Cells, and Cell Stacks}

\section{Gap \#12}

The application of seals to MEAs, cells, and cell stacks has not been developed for high-rate processes and is a manufacturing gap. MEAs require bonding, typically around the edges of the manifold connections. This prevents crossover and reactant leakage. The bipolar plates are sealed to the MEA either by compression of a polymer or using an adhesive bonding. Similarly, the cells are bonded to each other to form a cell stack. Using bonding materials for rapid component assembly is a well established manufacturing process. The processes need to be adapted for fuel cell applications.

Rapid sealing techniques are not adapted to the bonding of the MEAs to the bipolar plates. Present assembly processes are manual or batch processes that are not consistent with the development of roll goods processing. Higher rate assembly of the MEAs with the bipolar plates will be needed as the demand for fuel cell systems increases.

\section{Gap \#13}

Quality control of the seal thickness is critical for cell and cell stack assembly because seal thickness is designed to balance the compressive load on the fuel cell. Manufacturers will need to develop techniques that permit rapid, onsite application and measurement of seals.

\subsection{Manufacturing Gaps in Cell Stack Assembly}

\section{Gap \#14}

The equipment for rapidly assembling cell stacks has not been developed and is a manufacturing gap. Currently, PEM cell stacks are assembled manually. Rapid assembly equipment does not exist. Aligning the MEAs, bipolar plates, and end plates is critical to preventing the buildup of stress on cells when the stack is placed under compressive load.

\section{Gap \#15}

Manufacturers also need to develop quality control methods for rapid alignment of cell stack components. Correlations between cell alignment and cell stack durability need to be established. 


\subsection{Manufacturing Gaps for BOP}

The BOP components are listed in Table 5. Specific to the PEM fuel cell system are the membrane humidifier and water recovery device, the compressor/expander, the hydrogen recirculation pump, and the air blower. Manufacturers report they have the ability to manufacture the BOP components at high rates. Manufacturers would build the facilities for high-rate production if there was a demand for the devices.

\section{Gap \#16}

Integrating the components into the reactant delivery system and the thermal management system is a manufacturing gap.

\subsubsection{Membrane Humidifier and Water Recovery}

High volume production of the humidifier and water recovery devices is not a manufacturing gap. The humidifier has product specifications unique to PEM fuel cells and is manufactured at small scale consistent with PEM fuel cell demand. The manufacturing technology exists for the membrane reactors and can be adapted to PEM fuel cell requirements.

\subsubsection{Water Recovery}

Water recovery devices for PEM fuel cell systems can be manufactured. Water recovery using enthalpy wheels or condensers are used in combination with the membrane humidifiers to maintain the water balance of the PEM system. These devices are designed to match the PEM fuel cell system and large scale manufacturing is not available. Manufacturing technology for producing condensers or enthalpy wheels is available and can be adapted to fulfill the volume production requirements for the PEM fuel cells. The demand for the enthalpy wheel and condensers for PEM fuel cells has not been established.

\subsubsection{Hydrogen Recirculation Pumps}

The fabrication of hydrogen recirculation pumps is not a manufacturing gap. Manufacturing low-cost hydrogen recirculation pumps to meet PEM fuel cell needs has not been done; however the capability and manufacturing experience is available. Increased production requires purchase orders for the components. The demand is too low to proceed at this time.

\subsubsection{Compressor / Expander}

\section{Gap \#17}

Manufacturing a compressor/expander that fulfills the performance requirements of a PEM fuel cell is a manufacturing gap. Honeywell has reported that the data used for the projected compressor/expander are not based on a single device. The Honeywell data supplied to Argonne National Laboratory for modeling a PEM fuel cell were based on data from two separate devices. Honeywell believes that these devices can be manufactured as a single device. 
Table 5. The balance of plant components and manufacturers

\begin{tabular}{|l|l|}
\hline \multicolumn{1}{|c|}{ Component } & \multicolumn{1}{c|}{ Manufacturer } \\
\hline Membrane Humidifier \& Water & PermaPure \\
Recovery & Honeywell \\
& Parker Hannifin \\
Parker Hannifin \\
Hydrogen Recirculation Pump & DynEco \\
& H2 Systems \\
& Rietschle Thomas Puchheim GmbH \\
& Honeywell, \\
Compressor / Expander & Rietschle Thomas Puchheim GmbH \\
& Parker Hannifin \\
Air Blower & DynEco \\
& Phoenix Analysis and Design \\
High Temperature Radiators & Technologies (PADT) \\
& R\&D Dynamics \\
Low Temperature Radiators & Modine \\
& Dana \\
System Pumps / Electric & Modine Hannifin \\
Motors & Dana \\
Filtration / Regulators / & Parker Hannifin \\
Pressure Transducers & Dana \\
\hline
\end{tabular}

\subsection{Manufacturing Readiness}

A major gap in the fuel cell development process is the lack of manufacturing development activities by some companies while manufacturing teams wait for the technology development process to figuratively throw the developed product "over the wall" to manufacturing. Manufacturing engineering is considered an important part of the product development process by U.S. companies such as $3 \mathrm{M}$ and United Technologies and is part of management's role in research and development as discussed by Taguchi. ${ }^{13}$

Incorporating manufacturing engineering with technology development process is, however, well understood by North American and Japanese industry. Some U.S. based manufacturers (e.g., 3M and W. L. Gore Inc.) report progress with integrating manufacturing and product development.

\subsection{Status of Manufacturing}

Manufacturing technologies reflect the state of market demand for PEM fuel cells in 2007.

\subsubsection{Portable Power}

MEA manufacturing for portable applications is at a fabrication level in the range of one thousand MEAs per shift for the smaller (less than 50 watt) power plants. Increases in production capacity are planned and under way. The existing production techniques permit manufacturers to build CCMs with a picture frame structure and accurate registration of the anode and cathode layers. Production rates of 1,000 MEAs per shift are possible for the portable

${ }^{13}$ Genichi Taguchi, Subir Chowdhury, Yuin Wu, :'Taguchi's Quality Engineering Handbook”, John Wiley and Sons, Inc., 2005, ISBN 0-471-413348 
power industry. The MEAs built from these CCMs have active areas in the range of $25 \mathrm{~cm}^{2}$ to $50 \mathrm{~cm}^{2}$. The design characteristics of these MEAs for portable applications are consistent with the selective catalyst deposition method discussed in Section 2 for both internal and external manifold cell stack designs.

Quality control is based on sampling the CCMs and MEAs. Six sigma production quality levels are a recognized target for portable power fuel cell manufacturers, but manufacturers are not ready for this level of production quality control. In-line quality measurements for the CCMs, GDEs, and MEAs have not been developed. Registration of the anode and cathode catalyst layers on the membrane is achieved using fixtures to manually align the layers. The thickness and uniformity of the catalyst layers is determined by selective sampling. In some cases, the sampling is non-destructive; however the analytical process is off-line and time consuming.

The applications for the portable power plants are in many cases for the military. These applications have an anticipated power plant life of less than one week. There is a strong interest in developing portable power plants for consumer electronics such as laptops and cell phones with television capabilities. The commercial applications require power plants operating in the range of 4 watts. Downsizing the 4 watt power plants to be compatible with commercial electronics has not been accomplished. Large-scale, high-rate manufacturing of the fuel cells for commercial electronics has not been established and awaits the resolution of the development efforts. It appears a majority of the companies developing the 4-watt fuel-cell systems are based in Japan and Korea and these companies were not interviewed as part of our assessment.

\subsubsection{Telecommunications Backup Power \& Forklift Trucks}

PEM fuel cell systems for telecommunications backup power and for forklift trucks are in the early adoptor stage of development. The telecommunications systems are in the range of $5 \mathrm{~kW}$ devices. The forklift truck PEM systems range in power from $10 \mathrm{~kW}$ to $30 \mathrm{~kW}$ depending on the manufacturer.

MEA manufacturing for the backup power and forklift PEM power plants is governed by the development of these market applications. The production processes are currently at a laboratory or pilot plant scale. Researchers expect production rates in the range of 1,000 to 5,000 MEAs per month. The MEAs are larger than the portable power MEAs and are in the range of $100 \mathrm{~cm}^{2}$ to $500 \mathrm{~cm}^{2}$.

Several companies reported they were capable of high-rate production of CCMs or GDEs for these applications. Selectively depositing the catalyst layers onto the membrane and registration of these layers is achieved using pilot-scale manufacturing methods that can be scaled up to high rate production. These production processes include roll-to-roll manufacturing methods. The application of seals to the CCM, GDEs, or MEAs has not been automated for high-rate production.

Bipolar plate manufacturer is in the early pilot plant production level. Continuous high rate production of bipolar plate performs and the assembly of the preforms into bipolar plates is not developed. 
Assembly of the cell stack is a manual process. The early adoptor stage is only beginning to establish the demand for the PEM systems. Development of an automated, rapid stack assembly system for PEM is not required based on the demand for PEM stacks.

Assembly of the BOP is at a modular stage based on work stations. The workstation approach to assembly of the BOP is sufficient to fulfill the delivery needs.

\subsubsection{Stationary Power}

Residential power is the primary stationary application for PEM systems. In North America, the residential power units are in the $5 \mathrm{~kW}$ range. Residential power is in the early adoptor stage.

Production rates of less than 1,000 power plants per year and possibly less than 500 power plants per year represent the market. Manufacturing for these production rates is similar to that reported above for telecommunications and forklift PEM systems.

\subsubsection{Automotive Systems}

Manufacturing of PEM systems for automotive applications is on the order of 1,000 power plants per year industry wide. Individual companies project delivery of 100 vehicles this year.

There are some indications that the rate of PEM fuel cell vehicle development may be increasing and higher manufacturing rates will be needed:

- Honda (HMC) proposed limited production for next year of a fuel-cell sedan that will be in limited production next year.

- Honda also announced a unique mass-market hybrid fuel cell vehicle for the USA within two years, priced less than $\$ 25,000$.

- General Motors (GM) promised to hand over to individuals sometime this year 100 Chevrolet Equinox SUVs modified to run on fuel-cell power. ${ }^{14}$

- GM announced the transfer of 500 fuel cell experts to production engineering groups. ${ }^{15}$ This transfer is the early stage of setting up manufacturing facilities.

- Toyota announced the use of their fuel cell hybrid vehicle for commercial use. ${ }^{16}$

General Motors appears to be establishing the early stages for large scale manufacturing of PEM fuel cell automobiles. GM will initiate production engineering of fuel cell systems. Increases in MEA, bipolar plate, and cell stack assembly will be needed to address the development of vehicle systems.

\footnotetext{
${ }^{14}$ GM News \& Issues, September 17, 2006

$15 \mathrm{http}: / /$ www.gm.com/company/gmability/adv tech/400 fcv/index fc.html,as of July 10, 2007

16 Toyota New Release, April 19, 2007
} 


\section{Recommendations}

Based on our analysis of the status of manufacturing PEM fuel cells in the 2007 timeframe, we make recommendations on the following topics:

- Manufacturing R\&D gaps

- Concurrent technology development and manufacturing R\&D

- Future work on assessing the state of manufacturing of PEM fuel cells

\subsection{Manufacturing R\&D Gaps}

Manufacturing R\&D should be undertaken to address the following barriers to high-volume, low-cost manufacturing as outlined in the following sections.

\subsubsection{High-Volume MEA Processes}

Manufacturing gaps for high-volume MEA processes include:

- Registration of the planform with and edge seal design

- Adaptation of existing roll processing to MEA manufacturing

- In-line quality control measurements to determine:

○ membrane uniformity

○ catalyst distribution and physical properties

○ the alignment and registration of the anode and cathode layers

○ the uniformity and quality of the GDL with microlayer

- Manufacturing methods for depositing low loaded catalyst onto support materials

- Physical and chemical vapor deposition methods are approaches that may resolve this manufacturing gap.

- Quality control technology needs to be developed and might be adapted from the semiconductor industry to determine the distribution and uniformity of the low loaded catalyst layers.

- Methods to manufacture GDEs where the catalyst layer does not fully cover the GDL. Rapid and controlled selective deposition of the catalyst layer with a perimeter for an edge seal is a need for GDE manufacture.

- Controlling the quality, thickness, and distribution of the catalyst layer in the GDE. High rate measurement methods need to be developed to determine the thickness and distribution of the catalyst during manufacture.

- Manufacturing equipment for the rapid and continuous application of the GDLs to a 3layer CCM in an integrated production. 
- Heat treatment of the catalyst layer to cure the PSA ionomer. The hot pressing stage is a bottleneck to the production of MEAs. Continuous methods for curing the ionomer consistent with roll processing need to be developed.

\subsubsection{High-Speed Bipolar Plate Processes}

Manufacturing gaps for high-speed bipolar plate processes include:

- Optimized thermal control of the hot pressing process to provide high rate production of resin bonded bipolar plates

- Rapid die cutting and thermal processing stages for expanded graphite processing

- Quality control of the bipolar plate fabrication

- Determining the flatness and parallelism of opposite faces of the bipolar plate is critical

- The depth and uniformity of the flow fields need to be maintained within specification to assure proper distribution of reactants

- In-line quality measurements need to be developed for bipolar plate manufacture.

- Rapid heat treatment and chemical processing methods for sheet metal bipolar plates

- High rate welding processes for assembling multiple flow field designs for reactants and coolant.

\subsubsection{High-Speed Sealing Techniques}

Manufacturing gaps for high-speed sealing techniques include:

- The application of seals to MEAs, cells, and cell stacks for high rate processes

- In-line application of seals in roll goods production of MEAs

- Seal applications consistent with roll goods production at 10 to $100 \mathrm{ft} / \mathrm{min}$

- The application of seals for the bonding the MEAs to the bipolar plates

- Alignment and registration of the MEAs on the bipolar plates combined with rapid application and curing of the seal materials

- Quality control of the seal thickness for cell and cell stack assembly. Manufacturers will need to develop techniques that permit rapid, onsite application and measurement of seals.

\subsubsection{Stack Assembly Techniques}

Manufacturing gaps for stack assembly techniques include:

- Rapid cell stack assembly

$\circ$ The lack of automated, high-rate assembly of cell stacks is a barrier to the production of PEM systems.

- Aligning the MEAs, bipolar plates, and end plates to prevent the buildup of stress on cells when the stack is placed under compressive load 
- Manufacturers also need to develop quality control methods for rapid alignment of cell stack components.

- Correlations between cell alignment and cell stack durability need to be established.

\subsubsection{BOP Components and Fuel Cell Systems}

Manufacturing gaps for BOP components and fuel cell systems include:

- Integrating the components into the reactant delivery system and the thermal management system

- Industry is capable of manufacturing membrane humidifiers, enthalpy wheels, condensers, and hydrogen recirculation pumps.

- No demand for the BOP components exists and industry requires purchase orders to initiate large scale production.

- Manufacturing of a compressor/expander

- Technology demonstration is needed for the device prior to initiating manufacturing.

- No manufacturing barriers exist for the fabrication of many of the balance-of-plant components.

\subsubsection{Quality Control Processes}

In-line quality control measurements do not exist for many of the proposed manufacturing processes for PEM fuel cells. The issue was emphasized by the participants of the Workshop on Manufacturing R\&D for the Hydrogen Economy, Washington DC, July, 2005. The gap analysis conducted in this work reinforces the importance of quality control processes for manufacturing PEM fuel cell systems. Manufacturing gaps for quality control processes were identified with each of the components and are collected in the following:

- In-line quality control technologies do not exist and this is a critical barrier to advancing PEM fuel cell technology.

- Correlation of quality control parameters with durability and performance of PEM fuel cells has not been established; this is a critical barrier to advancing the technology.

- Modeling of the PEM fuel cell performance and durability with respect to manufacturing characteristics does not exist.

- The following are key quality control parameters that need to be established:

○ MEAs

Membrane uniformity

Catalyst distribution

Catalyst layer thickness

Catalyst layer porosity

GDL thickness uniformity 
GDL porosity uniformity

Microlayer composition and distribution of particles

Registration and alignment of the anode catalyst layer with the cathode catalyst layer

- Bipolar plates

Flatness and parallelism of the preforms and plates

Uniformity of the flowfield depths and widths

Quality of the bonding of the preforms to fabricate a bipolar plate

Quality of the welds for sheet metal bipolar plates

○ Seals

Alignment of the seals for CCM and GDE manufacture

Seal thickness for the CCM and GDE manufacture

Seal alignment and flow characteristics in the assembly of PEM cell stacks

Compressive load distribution on the seals during cell stack assembly

- Cell Stack Assembly

Rapid measurement of the alignment and registration of the cells can prevent the buildup of stresses at the edges of the cells when the stack is under compressive load

\subsection{Concurrent Technology Development \& Manufacturing R\&D}

Manufacturing R\&D must be paired with technology R\&D to accelerate product development for near-term market introduction of high-quality, low-cost PEM fuel cells. This is well understood by most U.S. industry; large companies have integrated technology and manufacturing engineering efforts linked to various forms of assessing technology readiness levels (TRLs) and manufacturing readiness levels (MRLs).

We believe that a gap exists and is growing between fuel cell technology development and manufacturing engineering for some small to medium sized companies. An often cited reason is the long lead time to develop a fuel cell market for automotive applications. This could have a negative impact on development of a supplier base for fuel cell powertrains.

Consequently, we recommend that federal support for manufacturing R\&D be provided as PEM fuel cell technologies are being developed for various applications. The manufacturing support would accelerate the development of portable power systems, backup power, stationary power, and industrial vehicles. The results of the manufacturing support would directly transfer to the PEM automotive applications. The transfer of the technology would be particularly applicable for CCM, GDE, MEA, and cell stack manufacturing. 


\subsection{Future Work}

This first assessment for DOE's manufacturing R\&D activity focused on (1) identifying the design considerations for PEM fuel cells that have a major impact on manufacturing, (2) summarizing the manufacturing processes now in use, and (3) identifying gaps between current manufacturing processes and those needed in the future.

We recommend the following work as a sequel.

\subsubsection{Assessment of Manufacturing Readiness Levels}

Further definition of manufacturing readiness levels for the seven applications ranging from portable systems to systems for heavy-duty vehicles. The use of manufacturing readiness definitions establishes a hierarchy for comparing fuel cell components. A stage gate process is used to qualify the PEM fuel cell system. MRL requirements form the decision process for the transitions through the gates toward commercialization. The MRLs for the respective stages are given in Table 6.

Table 6. Manufacturing readiness levels ${ }^{17}$

\begin{tabular}{|c|l|}
\hline Level & \multicolumn{1}{c|}{ Definition } \\
\hline $1-3$ & Manufacturing concepts Identified \\
\hline 4 & System, component or item validation in laboratory environment. \\
\hline 5 & $\begin{array}{l}\text { System, component or item validation in initial relevant environment. Engineering } \\
\text { application/bread board, brass board development. }\end{array}$ \\
\hline 6 & $\begin{array}{l}\text { System, component or item in prototype demonstration beyond bread board, } \\
\text { brass board development. }\end{array}$ \\
\hline 7 & System, component or item in advanced development. \\
\hline 8 & $\begin{array}{l}\text { System, component or item in advanced development. Ready for low rate initial } \\
\text { production. }\end{array}$ \\
\hline 9 & $\begin{array}{l}\text { System, component or item previously produced or in production. Or, the } \\
\text { system, component or item is in low rate initial production. Ready for full rate } \\
\text { production. }\end{array}$ \\
\hline 10 & $\begin{array}{l}\text { System, component or item previously produced or in production. Or, the } \\
\text { system, component or item is in full rate production. }\end{array}$ \\
\hline
\end{tabular}

The MRL definitions were developed by the Defense Logistics Agency and are consistent with the TRLs established by the Department of Defense. Applying these definitions to fuel cell manufacturing will provide a consistent calibration of the manufacturing gaps.

The MRL definitions must be used in conjunction with the product and the volume production levels required by the application. In MRL 8, low rate of initial production will be very different for the backup power PEM system than for the automotive PEM system. The low level production for the backup power system would be less than 100 per year while the low level PEM production for automotive would be greater than 10,000 per year.

Future work would analyze the applications and develop a manufacturing hierarchy for PEM fuel cell systems.

\footnotetext{
${ }^{17}$ Christensen, J., MRL Mapping Exercise”, Briefing to $\mathrm{H}_{2}$ Manufacturing Community of Interest, March 13, 2007
} 


\subsubsection{Analysis of Manufacturing Options for PEM Fuel Cells that Are Environmentally Benign}

The life cycle issues for the PEM fuel cell will impact the manufacturing cost of the PEM fuel cells. The high cost of platinum catalyst may require the development of a strong recycle market. The environmental impact of the disposal of PSA membrane materials can be a social and economic issue. Sustainability issues are a Working Group topic discussed by the U.S. Fuel Cell Council. ${ }^{18}$

Sustainability applied to manufacturing for PEM fuel cells with emphasis on developing environmentally benign processes is an area for future analyses.

\subsubsection{Biennial Updates to this Assessment}

The development of PEM manufacturing processes will impact the PEM fuel cell applications. A biennial update is recommended to consider the following topics:

1. The manufacturing development process on preferred technology approaches for PEM applications.

2. Manufacturing approaches that fulfill all the requirements for a PEM fuel cell application may not fulfill the requirements for all PEM fuel cells; e.g., manufacturing for stationary PEM fuel cells may not be consistent with the requirement for light-vehicle PEM fuel cells.

3. The impact of emerging technology on the PEM manufacturing - emerging technology may provide cost reductions and manufacturing process simplification.

4. Estimates of the non-recurring manufacturing engineering cost to achieve manufacturing capability.

5. The status of the supply network to support the PEM fuel cell BoP requirements.

\footnotetext{
${ }^{18}$ As of July, 2007, see http://www.usfcc.com/members/wg08members.htm
} 


\section{Appendix A. Manufacturing Tools}

Manufacturing engineering has established manufacturing tools and best practices for achieving quality and driving cost to a minimum. Many of these tools are well developed and practiced by some of the most successful companies in the world, including Motorola, GE, and Toyota. These best practice manufacturing tools are used to evaluate the manufacturing process and seek to streamline manufacturing to maintain and further develop high rate, continuous production.

\section{Lean Manufacturing}

Lean manufacturing is a business philosophy that goes beyond the manufacturing process and "develops principles to achieve high performance that adds value to customers and society." "Components of lean manufacturing are briefly discussed in the following. These principles can applied to manufacturing for the fuel cell industry.

\section{Just-in-Time (pull-production)}

Just-in-Time (JIT) minimizes inventory and the process that controls JIT is a signal system identifying the need to supply materials or fabricate a component/device. The term "Kanban" is the familiar name for the signaling mechanism that manages JIT.

\section{Continual Improvement (Kaizen)}

Continual evaluation of the manufacturing process has the objectives of eliminating waste, proper production sizing based on customer demand, continuous training and information sharing, and continual testing to optimize the production process.

\section{Eliminating Waste (muda)}

Eliminating waste is a means of reducing manufacturing cost by eliminating raw materials waste and waste of value-added materials. Optimizing the manufacturing processes by eliminating activities, manpower, and expenditures that do not improve the product is part of the process.

\section{Mistake-Proofing}

Mistake-proofing is avoiding uncontrolled manufacturing conditions that lead to errors. The concept restricts manufacturing procedures to assure that proper process conditions are maintained.

\section{$5 S$}

$5 \mathrm{~S}$ is an approach to maintaining an orderly and efficient work condition. The term refers to the Japanese words for (1) tidiness, organization and keeping only essential items in the work area; (2) orderliness in the workplace; (3) cleanliness; (4) standards for control and consistency; and (5) sustaining discipline for maintaining standards, safety, and efficiency. $5 \mathrm{~S}$ is a philosophy for the workplace that can be independent of JIT production.

\footnotetext{
${ }^{19}$ Jeffery Liker, "The Toyota Way: 14 Management Principles From The World's Greatest Manufacturer", McGraw Hill (2004) ISBN 0-07-139231-9
} 


\section{Taguchi}

Taguchi is a statistical method to improve quality and often involves Design of Experiments to minimize the number of variables analyzed to improve quality. Named after Genichi Taguchi, the proposed optimization of quality should be undertaken during product development and the development (adaptation) of manufacturing processes.

\section{Six Sigma}

Six sigma is the elimination of defects through management of the production process. The concept was developed by Motorola and refers to 3.4 defective parts per million (actually 4.5 standard deviations -4.5 sigma). The term six sigma refers to maintaining six standard deviations between the mean of a process and the mean specification limit. 


\section{REPORT DOCUMENTATION PAGE}

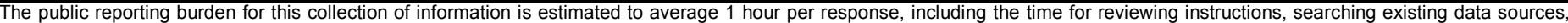

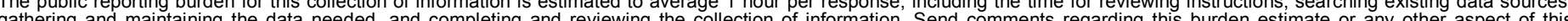

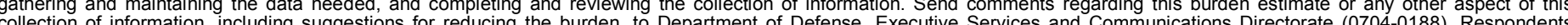

should be aware that notwithstanding any other provision of law, no pe

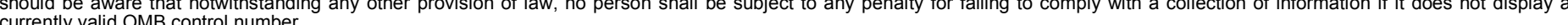

PLEASE DO NOT RETURN YOUR FORM TO THE ABOVE ORGANIZATION.

\begin{tabular}{l|l|l|l} 
1. REPORT DATE $(D D-M M-Y Y Y Y)$ & 2. REPORT TYPE & 3. DATES COVERED (FrOm - TO)
\end{tabular}

March 2008

Techncial Report

4. TITLE AND SUBTITLE

2007 Status of Manufacturing: Polymer Electrolyte Membrane

(PEM) Fuel Cells

5a. CONTRACT NUMBER

DE-AC36-99-G010337

5b. GRANT NUMBER

5c. PROGRAM ELEMENT NUMBER

6. AUTHOR(S)

Douglas Wheeler, George Sverdrup

5d. PROJECT NUMBER

NREL/TP-560-41655

5e. TASK NUMBER

$\mathrm{H} 2741100$

5f. WORK UNIT NUMBER

7. PERFORMING ORGANIZATION NAME(S) AND ADDRESS(ES)

National Renewable Energy Laboratory

1617 Cole Blvd.

Golden, CO 80401-3393

9. SPONSORING/MONITORING AGENCY NAME(S) AND ADDRESS(ES)

10. SPONSOR/MONITOR'S ACRONYM(S)

NREL

11. SPONSORING/MONITORING AGENCY REPORT NUMBER

12. DISTRIBUTION AVAILABILITY STATEMENT

National Technical Information Service

U.S. Department of Commerce

5285 Port Royal Road

Springfield, VA 22161

13. SUPPLEMENTARY NOTES

14. ABSTRACT (Maximum 200 Words)

In this document we assess the North American industry's current ability to manufacture polymer electrolyte

membrane (PEM) fuel cells.

15. SUBJECT TERMS

PEM; fuel cell manufacturing; MEA; bipolar plate; GDE; cell assembly; GDL; cell stack

\begin{tabular}{l}
\hline \multicolumn{3}{|l|}{ 16. SECURITY CLASSIFICATION OF: } \\
\hline \begin{tabular}{l|l|l|} 
a. REPORT & b. ABSTRACT & c. THIS PAGE \\
Unclassified & Unclassified & Unclassified \\
& & \\
\hline
\end{tabular} \\
\hline
\end{tabular}

\begin{tabular}{|c|c|}
\hline $\begin{array}{l}\text { 17. LIMITATION } \\
\text { OF ABSTRACT }\end{array}$ & $\begin{array}{l}\text { 18. NUMBER } \\
\text { OF PAGES }\end{array}$ \\
\hline UL & \\
\hline
\end{tabular}

19a. NAME OF RESPONSIBLE PERSON

19b. TELEPHONE NUMBER (Include area code) 